\title{
Produção acadêmica do tema internacionalização divulgada nos periódicos nacionais: Um estudo bibliométrico
}

\author{
Henrique César Melo Ribeiro ${ }^{1}$ \\ Universidade Federal do Piauí - UFPI, Parnaíba, PI, Brasil
}

\author{
DETALHES DO ARTIGO

\section{Histórico do artigo:} \\ Recebido em 16 de outubro de 2014 \\ Aceito em 09 de outubro de 2015 \\ Disponível online em 30 de abril de 2016 \\ Sistema de Revisão "Double Blind Review" \\ Editor científico: \\ Eduardo Eugênio Spers
}

\section{Palavras-chaves:}

Internacionalização

Produção acadêmica

Estudo bibliométrico

\begin{abstract}
RESUMO
Este estudo explorou a produção acadêmica do tema Internacionalização durante o período de 1999 a 2013 nas revistas Qualis Capes B2 a A2 (triênio 2010-2012). Metodologicamente, utilizaram-se as técnicas de análise bibliométrica e de rede social. Os principais achados foram: Borini, Scherer, Amal, Ferreira e Gomes se destacaram na rede de coautoria deste estudo, no que se refere a centralidade de grau. As Instituições de Ensino Superior (IESs): USP, ESPM e Uninove se sobressaem na rede social das IESs, no que tange ao degree. Todas as redes sociais visualizadas neste trabalho, têm baixas densidades. E os temas mais publicados foram: empresas multinacionais, negócios internacionais, inovação, estratégia competitiva, tecnologias, desempenho exportador, pequenas e médias empresas (PMEs), mercados internacionais, marketing internacional e estratégias internacionais. Estes assuntos que ficaram em destaque neste estudo, são inerentes à internacionalização, mostrando coerência ao tema explorado e, sobretudo que este assunto é amplo, pois ele aborda temáticas preponderantes para o melhor entendimento e compreensão dos processos que norteiam a internacionalização no contexto mundial.
\end{abstract}

C 2016 Internext | ESPM. Todos os direitos reservados!

\section{Introdução}

O tema internacionalização é essencial para países e organizações, uma vez que colabora para o aperfeiçoamento econômico da nação e tornam as organizações menos subordinadas ao mercado corporativo de cada país (Kovacs; Moraes e Oliveira, 2011). E as premissas contidas nas teorias da internacionalização ajudam a entender a importância do referido tema no contexto empresarial (Borini et al., 2006). Estas premissas versam que as organizações começam suas exportações tarde e fazem sua inclusão no mercado corporativo mundial de maneira pausada e sequencial (Machado Neto e Almeida, 2008).

Entretanto, só se pode entender um determinado campo do conhecimento e/ou tema se antes compreendermos como ele esta sendo gerado, divulgado, disseminado e socializado na literatura acadêmica, sobretudo, no âmbito brasileiro. E a análise da produção científica dos artigos divulgados sobre esta área da ciência e/ou temática é preponderante para melhor compreendermos, como ela esta crescendo e evoluindo no contexto acadêmico nacional. Realça-se as técnicas de análise bibliométrica e de rede social (Ribeiro, 2014), pois são essenciais para explorar todas as nuances que se fazem inerentes e necessárias para melhor compreensão sobre assuntos de vanguarda, que é o caso da Internacionalização na literatura cientifica brasileira.

A questão de pesquisa que norteará os alicerces deste estudo: Qual a representação da produção acadêmica do tema Internacionalização durante o período de 1999 a 2013 nas revistas Qualis Capes B2 
a A2 (triênio 2010-2012)? E o objetivo geral que ajuda a responder a referida questão deste trabalho é: explorar a produção acadêmica do tema Internacionalização durante o período de 1999 a 2013 nas revistas Qualis Capes B2 a A2 (triênio 20102012).

Observa-se que outros estudos de intenção similar a este já foram publicados, são eles: Gomes, Oliveira e Vieira (2011), Santos et al. (2011), Ferreira, Serra e Almeida (2012), Guido e Lima (2012), Scarpin et al. (2012), Souza e Fenili (2012), Ferreira et al. (2013), Guimarães, Tadeucci e Oliveira (2013), Kneipp et al. (2013) e Ferreira, Cavalcanti Neto e Gomes (2014), González-Valiente (2015), Moraes, Strehlau e Turolla (2015) e Ogasavara et al. (2015). Verifica-se que todos estes trabalhos são recentes, ou seja, ainda estão em estado da arte, porém, o estudo que será realizado agora, contribuirá para fomentar e aperfeiçoar, mediante de novos indicadores bibliométricos e de rede social, as pesquisa já realizadas sobre a produção cientifica do tema internacionalização, minimizando gaps que ainda existem sobre o conhecimento desta temática, em especial na literatura acadêmica nacional, por meio dos papers evidenciados das revistas B2 a As Qualis Capes das áreas de administração, contabilidade e turismo.

Este estudo se prontifica em mensurar indicadores recentes sobre a produção cientifica do assunto internacionalização, contribuindo na incorporação não só de novas variáveis bibliométricas, mas também, complementando-as através de indicadores de rede social que ajudaram a entender e compreender como os atores se conectam quando ocorre a publicação, divulgação, disseminação e socialização de artigos sobre a temática internacionalização no âmbito científico brasileiro.

\section{Internacionalização: conceito, teorias e produção acadêmica}

A internacionalização de empresas é um fenômeno presente em países desenvolvidos e emergentes (Pereira Leite e Moraes, 2014) e por isso, vem cada vez mais despertando o interesse de pesquisadores há décadas (Spohr e Silveira, 2012), influenciando na sua evolução no âmbito corporativo, em multinacionais (Pereira, 1976; Costa e Porto, 2013) e em PME; e no cenário acadêmico, sobretudo também por causa da discussão de suas teorias na literatura acadêmica (Moreira, 2009).

São sete as Teorias de internacionalização, são elas: "o Modelo do Ciclo de Vida do Produto, Uppsala - Escola Nórdica de Negócios Internacionais, Relacionado à Inovação, Escolha Adaptativa, Paradigma Eclético de Internalização (OLI), Modelo de Internacionalização Baseado em Recursos (RBV) e o Modelo Diamante" (Moraes; Oliveira; Kovacs, 2006, p. 128).

Para Kovacs, Moraes e Oliveira (2007), apesar destas teorias serem consideradas por alguns pesquisadores incompatíveis entre si, observa-se a interseção de alguns conceitos-chave, como por exemplo, o modelo diamante e a RBV por suas respectivas abordagens sobre vantagem competitiva nos negócios internacionais; e o modelo de ciclo de vida, com o Uppsala, com a escolha adaptativa e com o modelo diamante, pois, podem ser considerados processuais, pois descrevem o processo de internacionalização das organizações (Kovacs; Moraes; Oliveira, 2007).

Observa-se que a internacionalização pode ser considerada uma política que influencia no aperfeiçoamento, (Guedes, 2006), por meio de seus processos (Hilal e Hemais, 2003), em empresas multinacionais (Paiva e Hexsel, 2005) e em PME (Cortezia e Souza, 2011; Floriani e Fleury, 2012). Pode-se entender que a internacionalização é um processo estratégico que se torna uma condição imprescindível para a perpetuidade das organizações (Pereira Leite e Moraes, 2014).

Realça-se que nos últimos anos, diversos estudos sobre a produção cientifica do tema internacionalização foram sendo divulgados em periódicos nacionais. Versa-se a seguir alguns destes trabalhos, que serão eficazes para ajudar na discussão dos resultados desta pesquisa.

Gomes, Oliveira e Vieira (2011) levantaram a produção cientifica sobre internacionalização de empresas no Programa de Mestrado em Ciências Contábeis da UERJ, visando investigar a quantidade de trabalhos publicados no período de 2006 a 2009. Os achados da pesquisa mostram que foram aprovados, na área temática pesquisada, 34 trabalhos no período investigado. A maior frequência em relação aos autores foi a produção de Gomes, Oliveira e Barros, com respectivamente 29, 10 e 
quatro artigos publicados. Os trabalhos, em maioria, foram elaborados em rede.

Santos et al. (2011) mapearam as publicações sobre internacionalização nos anais do Enanpad de 2005 a 2009. Foram identificados 58 artigos. Examinaram que maior parte das publicações concentrou-se nos anos de 2008 e 2009. Constataram predominância de estudos publicados com dois autores; um crescimento do tema internacionalização alcançado seu ápice em 2009. Concluíram que pesquisas sobre internacionalização precisam ser mais exploradas no meio da literatura acadêmica nacional.

Guido e Lima (2012) fizeram uma pesquisa bibliométrica sobre os temas empresas transnacionais e internacionalização de 1993 a 2012. Foi identificada 142 estudos a partir da base de dados do Web of Science. Entre os principais achados, os autores observaram que os trabalhos sobre estes temas estão concentrados em países como Inglaterra, Estados Unidos da América (EUA), Alemanha e Austrália. Concluíram que o tema internacionalização e o conceito de empresa transnacional ainda permitem um campo fértil para novas descobertas.

Scarpin et al. (2012) levantaram a produção cientifica do tema cluster e internacionalização nos periódicos de alto impacto brasileiros de 2000-2010. Foram identificados 28 artigos, sendo que a maior parte deles publicado em 2008. A vinculação dos autores mostrou-se bastante diversificada, com 25 IESs, sendo a mais representativa a UFSC e com grande concentração nas instituições das regiões sul e sudeste. A maior parte das produções, 50\%, deu-se com dois autores.

Souza e Fenili (2012) identificaram e discutiram a produção científica sobre internacionalização de empresas para apresentar uma agenda de pesquisa. O período analisado na produção acadêmica brasileira e estrangeira foi de 2005 a setembro de 2011, sendo selecionados 141 artigos. Observaram uma carência de trabalhos que promovessem uma discussão direta sobre a relação entre internacionalização e cultura, especialmente no que concerne às iniciativas brasileiras.

Guimarães, Tadeucci e Oliveira (2013) realizaram uma análise bibliométrica sobre gestão intercultural, internacionalização e mobilidade acadêmica. Os resultados obtidos observam a carência da área de produção científica de pesquisas que agregassem os temas gestão intercultural, internacionalização e instituições de ensino superior. Concluíram que estes temas estão em franco crescimento, considerando o contexto intencional.

Kneipp et al. (2013) analisaram as publicações relacionadas ao tema internacionalização nos periódicos e congressos vinculados ao Enanpad de 1997 a 2010. 122 estudos foram identificados. Verificaram que as publicações ocorreram em maior número a partir de 2006, colocando em evidencia as revistas RAC e BAR. A maioria das publicações tem entre dois e três autores. As IESs que mais publicaram foram: UFRJ, USP, UFPR e UFRGS.

Ferreira, Cavalcanti Neto e Gomes (2014) identificaram e discutiram o perfil da produção científica e a evolução do tema internacionalização de empresas nos artigos publicados na biblioteca eletrônica de periódicos científicos (SPELL) no período 2009-2013. 174 artigos foram identificados. Constataram que as pesquisas com dois ou três autores ocorrem com maior frequência e que a área apresentou uma evolução de 2010 a 2012 em relação ao número de artigos publicados e se caracteriza por estar baseada em teorias consolidadas tanto da perspectiva econômica quanto da comportamental.

González-Valiente (2015) analisaram as citações do periódico Internext durante o período de 2006 a 2013. O autor observou que os artigos mais citados tem relação forte com as temáticas de Teoria e estratégias de internacionalização, análises de transação e governança corporativa.

Moraes, Strehlau e Turolla (2015) analisaram a pesquisa científica brasileira em Internacionalização de Empresas, mediante a revisão de todos os artigos publicados na área nos periódicos classificados como Qualis A pela CAPES, no período de 2001 a 2014. Os autores constaram um destaque do periódico RAC nas publicações sobre o citado tema. Os temas mais abordados foram: Escola de Uppsala, Empreendedorismo e Teorias de redes. As IESs que se destacaram foram: PUC (MG), USP, FGV-SP, ESPM, UFRGS e Unisinos. E os autores que ficaram em realce foram: Rezende, S. F. L., Borini, F. M., e Versiani, A.

Ogasavara et al. (2015) examinaram pesquisas recentes sobre a internacionalização de empresas multinacionais brasileiras com base na análise de 174 artigos publicados que apareceram em periódicos acadêmicos, livros e conferências internacionais e 
brasileiras. Os acadêmicos observaram que a predominância de artigos publicados em parceria; os autores Oliveira Júnior, Fleury e Borini ficaram em realce.

Observando as oito pesquisas contempladas nos parágrafos anteriores, verifica-se uma similaridade entre elas, em especial, estudos bibliométricos sobre o tema internacionalização, sendo ele pesquisado individualmente ou com outro(s) tema(s) em conjunto. Constatou-se serem trabalhos em sua maioria buscando investigar e identificar a produção acadêmica do assunto internacionalização, pegando por base os bancos de dados de congressos e/ou revistas nacionais. Pode-se notar também que alguns destes estudos evidenciam e colocam a internacionalização como assunto em evolução na literatura acadêmica.

Entretanto, nenhum destes oito trabalhos vistos anteriormente, buscou pesquisar o tema internacionalização em 62 periódicos acadêmicos nacionais do Qualis Capes, pegando como amostra os extratos de notas B2 a A2. A pesquisa que é proposta neste estudo se torna mais recente e ampla, podendo com isso influenciar na mitigação de gaps que ocorreram em relação aos oito estudos bibliométicos enfatizados antes, que versam sobre a produção cientifica da temática internacionalização.

Por entender, que o estudo que está sendo realizado neste paper é o mais atual por abarcar uma gama superior de periódicos nacionais e consequentemente uma quantidade de trabalhos maior, esta pesquisa contribuirá para mostrar como esta a recente produção científica da temática internacionalização nos últimos 15 anos, colaborando com isso para fornecer informações que poderão ser úteis para o aperfeiçoamento, fomento e uma maior socialização dos estudos sobre Internacionalização na literatura acadêmica nacional.

\section{Método de pesquisa}

O objetivo deste estudo foi explorar a produção acadêmica do tema Internacionalização durante o período de 1999 a 2013 nas revistas Qualis Capes B2 a A2 (triênio 2010-2012), nas áreas de administração, contabilidade e turismo.

Para se conseguir explorar a produção acadêmica do tema Internacionalização, utilizou-se das técnicas de análise bibliométrica e de rede social (Ribeiro, 2014). A bibliometria foi usada neste estudo para aferir as seguintes variáveis: evolução do tema, evidenciação do tema mediante os periódicos, autoria, autores, IESs, estados e países.

Realça-se que além da bibliometria, utilizou-se a cienciometria, com o foco de identificar domínios de interesse, em especial, os temas (Pacheco \& Kern, 2001) que versam e que tem relação ao tema principal que é explorado neste estudo, para melhor compreender e entender o campo do conhecimento científico Internacionalização na literatura acadêmica brasileira.

Neste cenário, versa-se que os estudos bibliométricos podem contribuir no trabalho de sistematizar as pesquisas realizadas num determinado campo do saber e endereçar problemas a serem averiguados em pesquisas futuras. Desta forma, é viável contemplar que o conhecimento científico é desenvolvido de forma gradual e a bibliometria ajuda a aperfeiçoar estes citados campos do saber (Chueke e Amatucci, 2015).

E a técnica de análise de redes sociais, foi agregada para calcular as variáveis das redes sociais dos autores, das redes sociais das IESs e das redes sociais dos estados/países. E também, para aferir os nós, laços, densidade, centralidade de rede, sobretudo o degree, ou seja, a centralidade de grau das respectivas redes sociais deste estudo.

Retornando ao enfoco da bibliometria, entendese que o rigor nesses estudos é caracterizado pela observação das premissas que administram cada um dos métodos. Por exemplo, no caso específico do método bibliométrico é confiado que os autores atendam às Leis que alicerçam esses estudos (Chueke e Amatucci, 2015), que são: Lei de Lotka, Lei de Bradford e Lei de Zipf. A Lei de Lotka, tem como escopo medir a produtividade dos pesquisadores, mediante um modelo de categorização, dimensão e assiduidade dos diversos autores em um conjunto de textos científicos (Leite Filho, 2008).

A Lei de Bradford relaciona à disseminação da literatura das revistas acadêmicas (Beuren e Souza, 2008), ou seja, mensura as revistas em ordem decrescente de produtividade de papers sobre uma determinada temática, aferindo um núcleo de periódicos que se destacam e são devotados ao tema ora explorado (Beuren e Da Silva, 2014).

Já a Lei de Zipf tem o objetivo de calcular a frequência do surgimento das palavras em vários textos científicos (Ferreira, 2010). Assim, é suscitada 
uma classificação coordenada de termos de um determinado tema (Vanti, 2002), porém, realça-se que para este trabalho, não foi usada como embasamento bibliométrico esta lei.

Visualmente, uma rede social é comparável a um encadeamento, com um conjunto de nós interconectados e estes nós são simulados pelos pontos de conexão dos atores (Ducci e Teixeira, 2011), aqui representados pelos autores, IESs e estados/países. Os nós representam os atores, e os laços são formados a partir das vinculações entre os atores (Martins et al., 2010). Estes laços podem ser fortes e fracos. Os laços fortes são compostos por amarrações mais frequentes e de uma constância extensa, com dois ou mais atores, compondo redes sociais coerentes e associadas (Corrêa e Vale, 2014).

A densidade é uma das mais comuns mensurações na análise de rede social (Albuquerque Filho e Machado-Da-Silva, 2009), em benefício de aferir a intensidade do intercâmbio dos atores da rede social. O seu calculo contribui para a formulação de hipóteses sobre as informações que cercam pela rede (Mello, Crubellate e Rossonl, 2010), podendo ser aperfeiçoada tanto para a rede social dos autores, quanto também para a rede social das IESs e estados/países, colaborando para o entendimento melhor do grau de centralidade de uma rede social. Neste panorama, existem três formas mais comumente usadas para calcular esse tipo de avaliação: centralidade de grau (degree); centralidade de proximidade (closeness); e centralidade de intermediação (betweenness).

Para conseguir explorar os artigos sobre o tema Internacionalização, foram escolhidas as revistas brasileiras classificadas com a nota A1 a B2 pela Qualis Capes das áreas de Administração, Contabilidade e Turismo. Chegou-se à relação relacionada no Quadro 1. Justifica-se trabalhar a classificação A1 a B2, devido a mesma contemplar uma maior qualidade de periódicos, influenciando também em uma maior qualidade dos artigos divulgados nestes meios de divulgação.

A Tabela 1 divulga que neste trabalho foram analisados 62 periódicos acadêmicos nacionais. A coleta de dados foi atingida procurando, nestes periódicos, manuscritos publicados entre 1999 a 2013. Cada um destes periódicos passou por procedimento de busca de artigos que retribuíssem ao tema Internacionalização. Em todos os papers publicados, a disponibilidade dos mesmos foi em meio eletrônico. Os textos acadêmicos publicados foram acessados diretamente dos respectivos sites dos periódicos, sendo, que a procura foi realizada de forma esmiuçada, para com isso, achar todos as pesquisas que apresentassem as palavras-chave: Internacionalização, internacional; internacionais; multinacionais; multinacional; subsidiárias; subsidiária; exportação; global; transnacional, Internationalization, international, internationals, multinationals, multinational, subsidiaries, subsidiary, export, global e transnational. no título, no resumo ou nas palavras-chave de cada artigo publicado.

Ao determinar um corte por meio das mencionadas palavras-chave foi focado e alinhado o estudo com a questão de pesquisa afim de que todos os artigos identificados tivessem pelo menos uma das palavras-chave, ou no título, ou no resumo e/ou nas palavras-chave de cada trabalho. Não se ampliou o número de palavras-chave na busca de artigos sobre - tema internacionalização, para evitar que suscitassem outras abordagens que para este estudo não teriam relevância. Foram identificados assim, artigos que possuíam aderência integral ao conteúdo Internacionalização, compondo com isso os textos científicos objeto do estudo. Pode-se entender e compreender então, que o mencionado filtro apresentou um agrupamento específico sob a área que caracteriza a abordagem Internacionalização em todas as suas nuances acima especificadas.

As palavras-chave não foram examinadas de forma simultânea, para que fossem elegidos todas os artigos que tivessem ao menos uma das palavraschave antes descritas. $O$ discernimento usado para a eleição dos manuscritos foi fundamentado no acontecimento das palavras-chave anteriormente citadas e com isso encontradas não concomitantemente no título, no resumo e nas palavras-chave dos papers deste estudo.

A coleta de dados regressou 407 artigos que foram analisados de maneira quantitativa. Os dados sobre cada manuscrito foram modificados em informações e capturadas usando o software Bibexcel e as reproduções das figuras foram feitas usando os softwares UCINET 6 for Windows e Microsoft Excel 2007.

\section{Análise e discussão dos resultados}

O propósito desta seção é contemplar a análise e discussão dos resultados dos 407 artigos identificados. 
Tab. 1

Classificação dos periódicos, triênio (2010-2012)

\begin{tabular}{|c|c|c|c|}
\hline Revista & Sigla & ISSN & Nota \\
\hline Brazilian Administration Review & BAR & $1807-7692$ & $\mathrm{~A} 2$ \\
\hline Brazilian Business Review & BBR & $1807-734 \mathrm{X}$ & $A 2$ \\
\hline Gestão \& Produção & G\&P & 1806-9649 or 0104-530X & $\mathrm{A} 2$ \\
\hline Organizações \& Sociedade & O\&S & $1984-1413-9230$ or $585 x$ & $\mathrm{~A} 2$ \\
\hline RAC Eletrônica & RAC-e & $1981-5700$ & $A 2$ \\
\hline Revista de Administração Contemporânea & RAC & $1415-6555$ ou $1982-7849$ & $A 2$ \\
\hline RAE Eletrônica & RAE-e & $1676-5648$ & A2 \\
\hline Revista de Administração de Empresas & RAE & $1415-6555$ ou $1982-7849$ & $\mathrm{~A} 2$ \\
\hline Rausp-e & Rausp-e & $1983-7488$ & $\mathrm{~A} 2$ \\
\hline Revista Brasileira de Economia & RBE & $0034-7140$ & $A 2$ \\
\hline Revista Contabilidade \& Finanças & $R C \& F$ & $1519-7077$ or $1808-057 X$ & $A 2$ \\
\hline Revista de Administração da USP & Rausp & 0080-2107 or 1984-6142 & $\mathrm{A} 2$ \\
\hline Revista de Administração Pública & RAP & 0034-7612 & $A 2$ \\
\hline Revista Base & BASE & $1984-8196$ or $1807-054 X$ & B1 \\
\hline Cadernos EBAPE.BR & EBAPE & $1679-3951$ & B1 \\
\hline Contabilidade Vista \& Revista & $C V \& R$ & $0103-734 x$ & B1 \\
\hline Contexto Internacional & $\mathrm{Cl}$ & 0102-8529 & B1 \\
\hline Economia Aplicada & EA & $1413-8050$ & B1 \\
\hline Economia e Sociedade & ES & 0104-0618 & B1 \\
\hline Economia Global e Gestão & EGG & $0873-7444$ & B1 \\
\hline Estudos Econômicos & EE & 0101-4161 & B1 \\
\hline Faces: Revista de Administração & Faces: & $1517-8900$ or $1984-6975$ & B1 \\
\hline Gestão \& Regionalidade & G\&R & $1808-5792$ or $2176-5308$ & B1 \\
\hline Produção & Prod. & $1980-5411$ or $0103-6513$ & B1 \\
\hline Nova Economia & NE & 0103-6351 & B1 \\
\hline Revista de Administração e Inovação & RAl & $1809-2039$ & B1 \\
\hline Revista de Administração Mackenzie & RAM & $1518-6776$ or $1678-6971$ & B1 \\
\hline Revista Eletrônica de Administração & READ & $1413-2311$ or $1980-4164$ & B1 \\
\hline Brazilian magazine of Finance & RBF & $1679-0731$ or $1984-5146$ & B1 \\
\hline Revista Brasileira de Gestão de Negócios & RBGN & $1983-0807$ or $1806-4892$ & B1 \\
\hline Revista Brasileira de Pesquisa em Turismo & Rbtur & $1982-6125$ & B1 \\
\hline Revista Contemporânea de Contabilidade & $\mathrm{RCC}$ & $2175-8069$ or $1807-1821$ & B1 \\
\hline Revista de Administração da UFSM & $\operatorname{ReA}$ & 1983-4659 & B1 \\
\hline Revista de administração da Unimep & RAU & $1679-5350$ & B1 \\
\hline Revista de Ciências da Administração & RCA & $2175-8077$ or $1516-3865$ & B1 \\
\hline Revista de Contabilidade e Organizações & $\mathrm{RCO}$ & $1982-6486$ & B1 \\
\hline Revista de Economia Contemporânea & REC & $1415-9848$ & B1 \\
\hline Revista de Economia Política & REP & 0101-3157 or $1809-4538$ & B1 \\
\hline Revista Universo Contábil & $R \cup C$ & $1809-3337$ & B1 \\
\hline Contabilidade, Gestão e Governança & CGG & 1984-3925 & B2 \\
\hline Contextus & CONT. & $1678-2089$ & B2 \\
\hline Enfoque: Reflexão Contábil & ERC & $1517-9087$ & B2 \\
\hline Gestão \& Planejamento & G\&P & $2178-8030$ & B2 \\
\hline Gestão \& Sociedade & G\&S & $1980-5756$ & $\mathrm{~B} 2$ \\
\hline Revista Eletrônica de Negócios Internacionais da ESPM & InternexT & $1980-4865$ & $\mathrm{~B} 2$ \\
\hline Organizações em Contexto & OC & $1809-1040$ ou $1982-8756$ & B2 \\
\hline Perspectivas Contemporâneas & PC & 1980-0193 & B2 \\
\hline Pretexto & PRET. & $1517-672 X$ ou $1984-6983$ & $\mathrm{~B} 2$ \\
\hline Revista de Administração, Contabilidade e Economia & RACE & $1678-6483$ or $2179-4936$ & B2 \\
\hline Revista Brasileira de Estratégia & Rebrae & $1983-8484$ & $\mathrm{~B} 2$ \\
\hline Revista Brasileira de Inovação & $\mathrm{RBI}$ & $1678-6483$ or $2179-4936$ & B2 \\
\hline Revista Eletrônica de Ciência Administrativa & Recadm & $1677-7387$ & $\mathrm{~B} 2$ \\
\hline Revista de Gestão da USP & REGE & $2177-8736$ ou $1809-2276$ & B2 \\
\hline Revista Alcance & Alcance & $1983-716 \mathrm{X}$ & $\mathrm{B} 2$ \\
\hline Revista Ambiente Contábil & Ambiente & $2176-9036$ & B2 \\
\hline Revista de Educação e Pesquisa em Contabilidade & Repec & $1981-8610$ & B2 \\
\hline Revista Economia \& Gestão & REG & $1984-6606$ & $\mathrm{~B} 2$ \\
\hline Revista Iberoamericana de Estratégia & RIAE & 2176-0756 & B2 \\
\hline Revista Pensamento Contemporâneo em Administração & RPCA & $1982-2596$ & B2 \\
\hline Revista de Gestão Organizacional & RGO & $1806-6720$ or $1983-6635$ & B2 \\
\hline Revista de Gestão Social e Ambiental & RGSA & $1981-982 X$ & $\mathrm{~B} 2$ \\
\hline Sociedade, Contabilidade e Gestão & SCG & $1982-7342$ & B2 \\
\hline
\end{tabular}

Fonte: Dados da pesquisa 


\subsection{Evolução do tema internacionalização}

A Figura 1 mostra a evolução que o tema internacionalização teve durante os 15 anos explorados.

Verifica-se que o tema internacionalização começou a crescer em 2004, alcançando seu ápice nos períodos de 2010 e 2013, sendo que ambos os anos com 60 artigos publicados. Neste panorama focam-se os estudos de Santos et al. (2011) e de Kneipp et al. (2013) que de certa maneira corroboram com os achados deste trabalho.

Os dados colocados em evidencia na Figura 1 deixam claro que o tema internacionalização vem ganhando espaço na literatura acadêmica de forma continua, mesmo tendo uma pequena queda em 2011, contudo, de maneira macro, as publicações sobre este tema deixam de ser emergente e se tornam maduros, por meio das pesquisas divulgadas pelos periódicos, explorados neste estudo.

Tais dados contribuem para demonstrar a importância que o tema internacionalização tem para o contexto literário acadêmico nacional, propiciando oportunidades de leituras de diversos papers, por parte de diversos stakeholders (pesquisadores, docentes, discentes, gestores etc), colaborando com isso para o maior discernimento, compreensão e disseminação deste assunto, cooperando também para a sua evolução não só no âmbito acadêmico, mas também no cenário empresarial no Brasil.

\subsection{Periódicos por ano}

Depois de observado e realizado o recorte de acordo com o que é evidenciado na seção métodos deste trabalho, foi criada a Tabela 2 que coloca em evidencia os 53 periódicos que publicaram artigos relacionados ao tema internacionalização de 1999 a 2013. O que equivale aproximadamente $85 \%$ das revistas analisadas neste trabalho. Tal percentual mostra e confirma que o tema internacionalização esta bem difundido na literatura acadêmica brasileira, indo ao encontro do que foi visualizado na Figura 1 deste estudo.

Observa-se que o periódico Internext foi o que mais divulgou trabalhos sobre internacionalização nos últimos 15 anos, com 75 manuscritos. E desde que iniciou seus trabalhos em 2006, a revista publica pelo menos um paper sobre o referido assunto todo o ano, conseguindo seu pico de publicações em 2013, com 17 artigos publicados. Esta informação vai ao encontro do que é a proposta principal deste veículo acadêmico que é a produção, publicação e divulgação de artigos que tenham relação com a área de Gestão Internacional, sendo considerada assim uma revista que norteia publicações e temas voltados para a área de Negócios Internacionais.

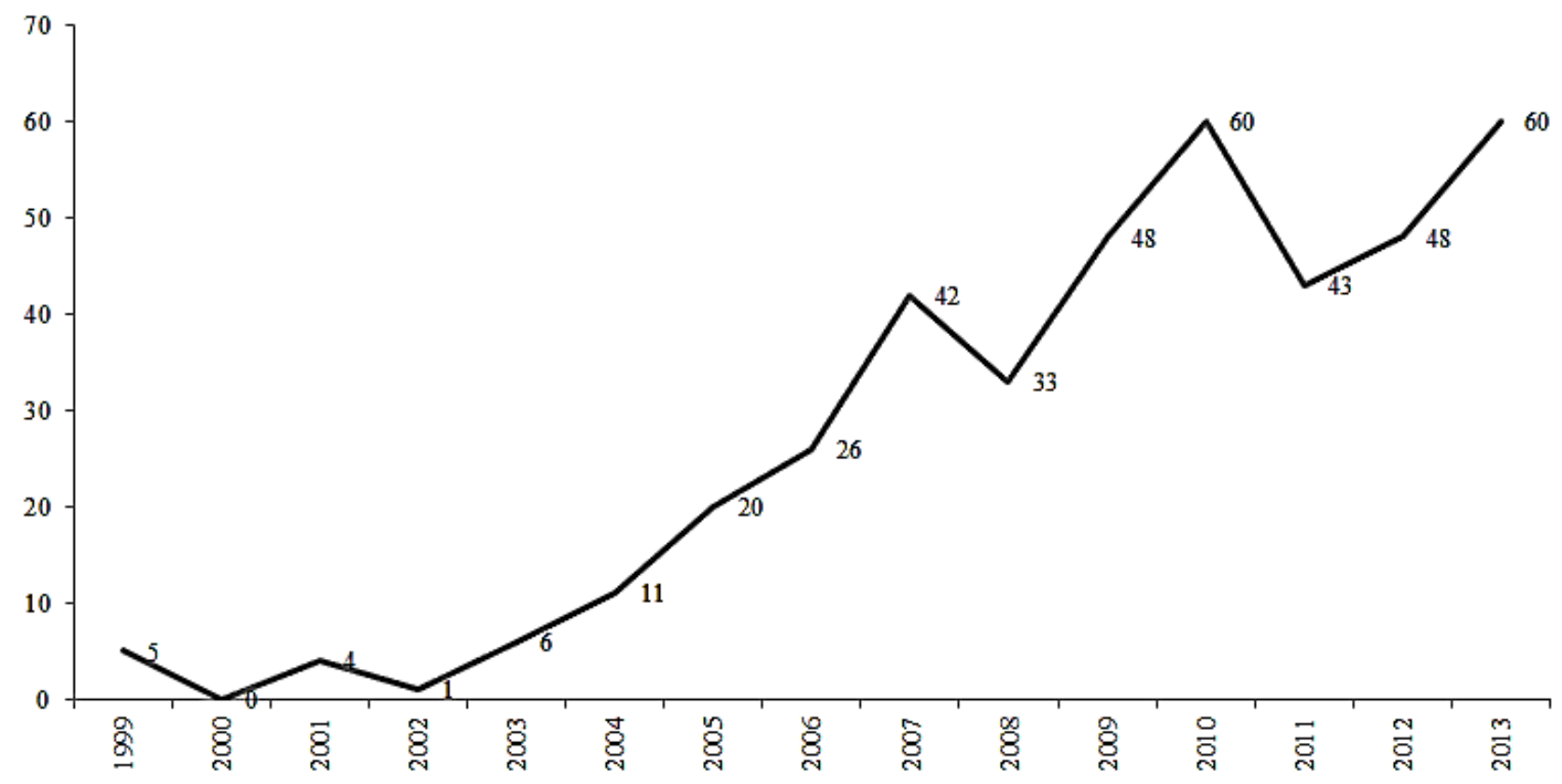

Fig. 1

Evolução do tema internacionalização

Fonte: Dados da pesquisa 
Tab. 2

Periódicos por ano

\begin{tabular}{|c|c|c|c|c|c|c|c|c|c|c|c|c|c|c|c|c|}
\hline Periódicos/Anos & 99 & 00 & 01 & 02 & 03 & 04 & 05 & 06 & 07 & 08 & 09 & 10 & 11 & 12 & 13 & Total \\
\hline Internext & & & & & & & & 9 & 7 & 3 & 8 & 11 & 11 & 9 & 17 & 75 \\
\hline RIAE & & & & & & & & 1 & 1 & & 2 & 3 & 6 & 4 & 6 & 23 \\
\hline Read & & & & & 1 & 1 & 3 & & 7 & 1 & 2 & 1 & 2 & 3 & 2 & 23 \\
\hline RAC & & & & & 2 & & 3 & 1 & & 1 & & 4 & 1 & 3 & 2 & 17 \\
\hline RAI & & & & & & & & 1 & 2 & 2 & 2 & 4 & 2 & & 4 & 17 \\
\hline BASE & & & & & & & & 1 & & 3 & 4 & 2 & 2 & 1 & 3 & 16 \\
\hline BAR & & & & & & & & 1 & 3 & 1 & 2 & 3 & 3 & 1 & 2 & 16 \\
\hline G\&P & 1 & & 1 & & 2 & 2 & 1 & 1 & & & 1 & 1 & 1 & 2 & 2 & 15 \\
\hline RAE & 2 & & & & & & 1 & 1 & 2 & & 3 & 1 & 1 & 2 & & 13 \\
\hline REGE & & & & & & 1 & & & 1 & & 1 & 2 & 2 & 1 & 4 & 12 \\
\hline Faces & & & & & & 1 & & 1 & & 2 & 2 & 2 & & 1 & 3 & 12 \\
\hline Rausp & & & & 1 & & & & 1 & 2 & & 1 & 2 & & 2 & 2 & 11 \\
\hline Alcance & & & & & & & 4 & 1 & & 1 & & & 1 & 1 & 2 & 10 \\
\hline Recadm & & & & & & 1 & & & 2 & & 1 & 2 & 3 & 1 & & 10 \\
\hline EGG & & & & & & & & & & 2 & 3 & 2 & 1 & 1 & & 9 \\
\hline RCA & & & & & & 1 & 1 & & 2 & & 1 & 1 & & 2 & & 8 \\
\hline RBI & & & & & & & & 1 & 1 & & 1 & 2 & & 1 & 2 & 8 \\
\hline RAU & & & & & & 1 & & & 2 & 2 & & 1 & & 1 & & 7 \\
\hline Rebrae & & & & & & & & & & 1 & & 2 & 1 & 1 & 1 & 6 \\
\hline RBGN & & & & & & 1 & & & & 1 & 1 & & & 1 & 2 & 6 \\
\hline Pretexto & & & & & & & 1 & & 1 & 1 & & 2 & & 1 & & 6 \\
\hline $\operatorname{ReA}$ & & & & & & & & & & 2 & & 1 & & 2 & 1 & 6 \\
\hline RAM & & & & & & & 1 & 1 & & 2 & 1 & & & & & 5 \\
\hline BBR & & & & & & & & 1 & & 1 & & 1 & 1 & & 1 & 5 \\
\hline G\&R & & & & & & & & & 1 & 1 & 1 & 2 & & & & 5 \\
\hline O\&S & 1 & & 2 & & & 1 & 1 & & & & & & & & & 5 \\
\hline Ebape & & & & & & & 1 & & & & 1 & 1 & & 1 & & 4 \\
\hline RUC & & & & & & & & & & 1 & 1 & 1 & & & 1 & 4 \\
\hline$E \& G$ & & & & & & & & 1 & 3 & & & & & & & 4 \\
\hline Contextus & & & & & & & & & 1 & 1 & & & 1 & 1 & & 4 \\
\hline$C V \& R$ & & & 1 & & 1 & 1 & & & & & & 1 & & & & 4 \\
\hline Produção & & & & & & & 1 & & & & 1 & & & 1 & 1 & 4 \\
\hline CGG & & & & & & & & & & & 1 & & 2 & & & 3 \\
\hline RGO & & & & & & & & & & & 1 & 1 & & 1 & & 3 \\
\hline $\mathrm{RCC}$ & & & & & & & & 1 & & 2 & & & & & & 3 \\
\hline Contexto Internacional & 1 & & & & & & & & & & 1 & & & 1 & & 3 \\
\hline GeS & & & & & & & & & & 1 & 1 & & & & & 2 \\
\hline RBE & & & & & & & & & 2 & & & & & & & 2 \\
\hline Organizações em Contexto & & & & & & & & 1 & & & & & 1 & & & 2 \\
\hline Estudos Econômicos & & & & & & & 1 & & & & 1 & & & & & 2 \\
\hline $\mathrm{RCO}$ & & & & & & & & & & 1 & & 1 & & & & 2 \\
\hline REP & & & & & & & 1 & & & & & & & 1 & & 2 \\
\hline SCG & & & & & & & & & & & 1 & & 1 & & & 2 \\
\hline RAP & & & & & & & & 1 & & & 1 & & & & & 2 \\
\hline Economia e Sociedade & & & & & & & & & & & & & & & 1 & 1 \\
\hline RAE Eletrônica & & & & & & & & & & & & 1 & & & & 1 \\
\hline RACE & & & & & & & & & & & & & & & 1 & 1 \\
\hline $\mathrm{Cl}$ & & & & & & & & & 1 & & & & & & & 1 \\
\hline ES & & & & & & & & & 1 & & & & & & & 1 \\
\hline RGSA & & & & & & & & & & & 1 & & & & & 1 \\
\hline Repec & & & & & & & & & & & & & & 1 & & 1 \\
\hline PC & & & & & & & & & & & & 1 & & & & 1 \\
\hline RACont & & & & & & & & & & & & 1 & & & & 1 \\
\hline Total & 5 & 0 & 4 & 1 & 6 & 11 & 20 & 26 & 42 & 33 & 48 & 60 & 43 & 48 & 60 & 407 \\
\hline
\end{tabular}

Fonte: Dados da pesquisa

González-Valiente (2015) corrobora, ao afirmar que a Internext, é um periódico que foca nos negócios internacionais, buscando responder questões que norteiam a gestão internacionais, no que se refere a estratégia, finanças, gestão de pessoas, estudos organizacionais dentre outros. Neste panorama, verifica-se que o destaque ao tema internacionalização evidenciado na Tabela 2 é salutar, visto que a citada revista, vislumbra em seu escopo outros assuntos, sobre negócios 
internacionais, e não somente sobre internacionalização.

Ressaltam-se também as revistas: RIAE, REAd, RAC, RAI, BASE, BAR, G\&P, RAE, REGE e Faces, com 23, 23, 17, 17, 16, 16, 15, 13, 12 e 12 manuscritos publicados de 1999 a 2013. Este achado vai ao encontro da Lei de Bradford (Beuren e Souza, 2008), que mensura a produtividade de revistas, estabelecendo, a posteriori, o núcleo de periódicos para a temática internacionalização. Sendo assim, o centro basilar deste estudo é composto pelos periódicos: Internext, RIAE, REAd, RAC, RAI, BASE, BAR, G\&P, RAE, REGE e Faces. Em outras palavras, estes meios de comunicação acadêmico são particularmente os que se destinam (Beuren \& Souza,
2008), de maneira mais frequente, à publicação e divulgação do tema Internacionalização na literatura acadêmica brasileira, em especial o periódico Internext, como já fora destacado antes.

A Figura 2 contempla os papers que se relacionam com a temática internacionalização por periódico. Por esta figura, tem-se a percepção mais aprofundada da revista Internext, e sua proeminência nas publicações sobre o assuntos em investigação.

Os dados e informações evidenciados nesta seção, contribuem para mostrar quais revistas dão maior realce ao tema objeto de estudo, cooperando assim para pesquisadores seniores e/ou iniciantes que buscam publicar e ter seus trabalhos sobre

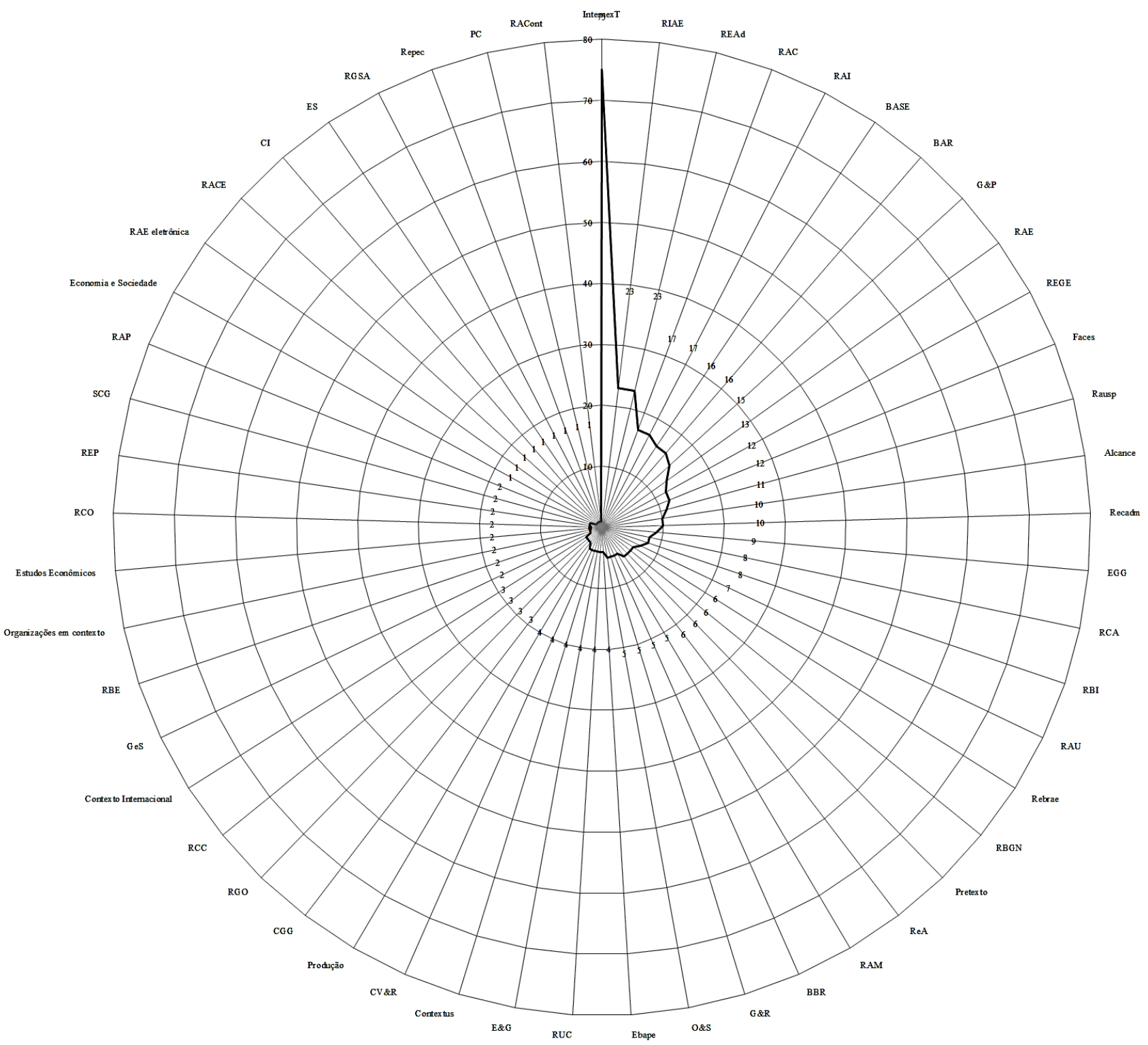

Fig. 2

Artigos relacionados a internacionalização e por periódico

Fonte: Dados da pesquisa 
internacionalização divulgados e socializados na literatura acadêmica nacional.

É importante ressaltar também que os periódicos que não ficaram em evidencia neste estudo, não significa que estes não possam publicar papers sobre internacionalização, mas sim é uma oportunidade para que os autores possam submeter seus manuscritos nestes meios de divulgação acadêmica, ocasionando com isso a posteriori que sejam publicados, influenciando de sobremaneira na ampliação de artigos sobre o tema aqui estudado.

\subsection{Características de autoria}

A Tabela 3 contempla as autorias dos 407 artigos identificados neste trabalho. maduros, emergentes e/ou embrionários. Pesquisar em parceria possibilita também a geração de grupos de estudos que contribuirão para a maior disseminação e socialização da ciência, que se manifesta por meio de estudos de temas importantes para o meio acadêmico e empresarial, como é o caso da temática internacionalização. Neste sentido, a referida temática esta sendo difundida de forma macro na literatura acadêmica brasileira, ao ser observado um realce na quantidade de seus estudos que são publicados e divulgados em conjunto nos meios acadêmicos de comunicação nacionais.

\subsection{Autores mais profícuos}

Depois de observado e efetivado o recorte de acordo

Tab. 3

Características de autoria

\begin{tabular}{cccccccccccccccccc}
\hline Autor/Anos & 99 & 00 & 01 & 02 & 03 & 04 & 05 & 06 & 07 & 08 & 09 & 10 & 11 & 12 & 13 & Total & $\%$ \\
\hline Autoria única & 3 & 0 & 1 & 1 & 2 & 1 & 8 & 6 & 9 & 3 & 8 & 7 & 3 & 6 & 4 & 62 & $15.23 \%$ \\
Dois autores & 2 & 0 & 3 & 0 & 2 & 8 & 5 & 14 & 20 & 12 & 20 & 15 & 19 & 16 & 23 & 159 & $39.07 \%$ \\
Três autores & 0 & 0 & 0 & 0 & 1 & 2 & 6 & 4 & 9 & 10 & 12 & 27 & 12 & 17 & 18 & 118 & $28.99 \%$ \\
Quatro autores & 0 & 0 & 0 & 0 & 1 & 0 & 1 & 2 & 3 & 8 & 7 & 10 & 8 & 6 & 11 & 57 & $14.00 \%$ \\
Cinco autores & 0 & 0 & 0 & 0 & 0 & 0 & 0 & 0 & 1 & 0 & 0 & 0 & 0 & 3 & 4 & 8 & $1.97 \%$ \\
Seis autores & 0 & 0 & 0 & 0 & 0 & 0 & 0 & 0 & 0 & 0 & 1 & 1 & 1 & 0 & 0 & 3 & $0.74 \%$ \\
\hline Total & 5 & 0 & 4 & 1 & 6 & 11 & 20 & 26 & 42 & 33 & 48 & 60 & 43 & 48 & 60 & 407 & $100.00 \%$ \\
\hline
\end{tabular}

Fonte: Dados da pesquisa

Nota-se que a maioria dos manuscritos publicados foram divulgados em parceria, ou seja, cerca de $85 \%$ dos papers foram divulgados em conjunto com dois até seis autores, sendo que a autoria com dois e três pesquisadores ficaram em evidencia. A pesquisa de Ogasavara et al. (2015) corroboram com os achados desta seção.

Ressalva-se que as publicações em parceria é uma característica que vem tomando força na literatura acadêmica nacional, sobretudo nas áreas de administração, contabilidade e turismo. Os achados relatados na Tabela 3, não são particulares somente do tema em questão, mas estes resultados são inerentes a diversos temas das áreas de administração, contabilidade e turismo.

Isto mostra que a publicação em parceria é uma estratégia essencial para fazer com que um determinado tema e/ou campo do conhecimento seja fomentado na academia, proporcionando uma maior ativação de pesquisas sobre diversos assuntos com o que é contemplado na seção métodos deste estudo, foi criada a Figura 3 que aprecia os 654 autores que ajudaram a publicar os 407 estudos sobre internacionalização desta pesquisa, colocando em evidencia os 18 mais profícuos.

Constata-se que o autor Borini, foi o que mais publicou durante os 15 anos de estudos sobre o tema internacionalização, com 26 publicações. Em seguida vêm os pesquisadores: Scherer, Moraes, Ferreira, Oliveira Júnior e Fleury, com 14, 12, 12, 12 e 11 publicações respectivamente. No que tange ao autor Borini, os acadêmicos Moraes, Strehlau e Turolla (2015), em sua pesquisa, corroboram com os achados desse estudo. E além do realce ao pesquisador Borini, os autores Ogasavara et al. (2015), confirmam os resultados desta seção, ressaltando a importância dos acadêmicos Oliveira Júnior e Fleury, para a difusão do tema internacionalização na literatura acadêmica nacional. 


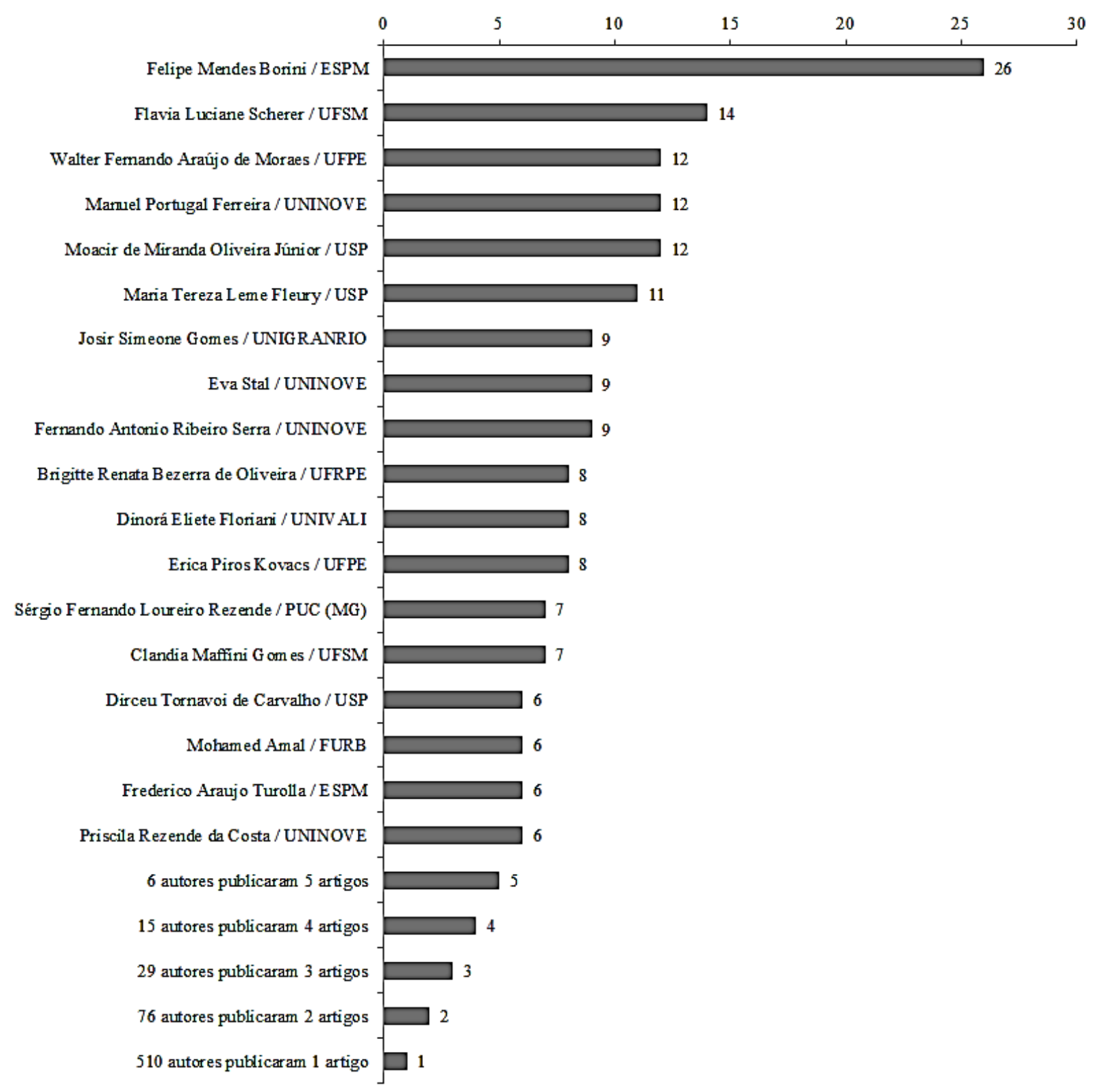

Fig. 3

Autores

Fonte: Dados da pesquisa

Com nove papers tem os articulistas: Gomes, Stal e Serra. Já com oito artigos vêm os autores: Oliveira, Floriani e Kovacs. Com sete publicações aparecem os acadêmicos: Rezende e Gomes. E com seis publicações surgem os pesquisadores: Carvalho, Amal, Turolla e Costa.

18 acadêmicos publicaram de seis a 26 artigos; 50 autores publicaram de três a cinco papers; 76 pesquisadores divulgaram dois manuscritos; e a grande maioria, ou seja, 510 articulistas, publicaram apenas uma vez. Tal dado remete a Lei de Lotka, pois a citada lei aferi a produtividade dos autores (LEITE
FILHO, 2008), realçando que poucos autores costumam publicar muito e muitos autores habituam-se a publicar pouco (RIBEIRO, 2014), o que remete as informações evidenciadas nesta seção.

Outro dado interessante contemplado nesta seção é que, dos 18 autores mais profícuos, 11 são oriundos de IESs da região Sudeste; quatro são de IESs da região Sul; e três da região Nordeste. Sendo que as IESs que se destacaram aqui foram a Uninove (quatro pesquisadores), USP (três autores), UFSM, ESPM e UFPE, todas com dois pesquisadores cada. 
4.5 IESs que mais publicaram

A Figura 4 mostra as 169 IESs que participaram deste estudo, realçando as 20 IESs mais proliferas. cada. O que mostra que mesmo o tema internacionalização ter crescido nos últimos 15 anos, em especial a partir de 2004, ainda pode evoluir mais, principalmente se estas IESs que publicaram menos

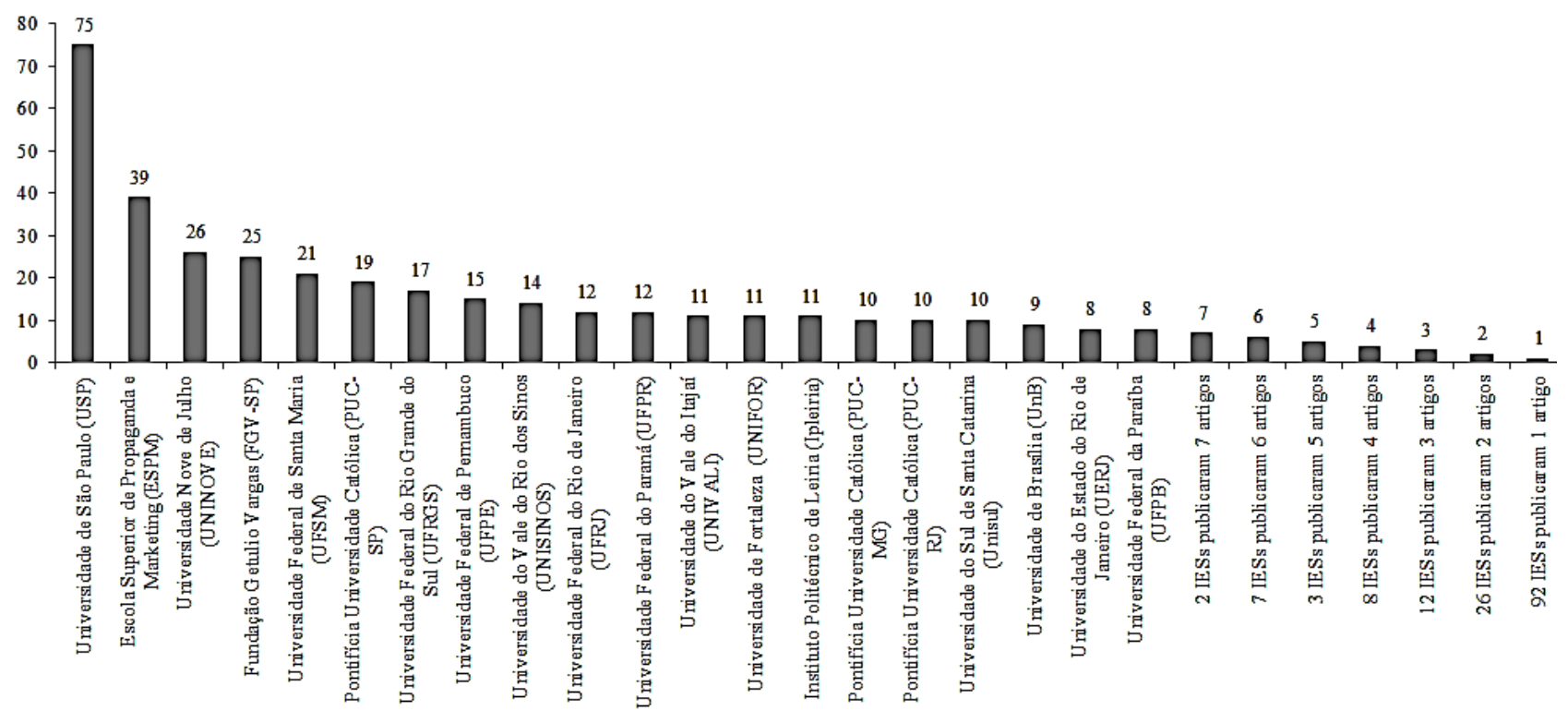

Fig. 4

IESS

Fonte: Dados da pesquisa

Contempla-se a USP como a mais profícua dentre as 169 IESs identificadas neste estudo. A USP por meio de seus pesquisadores que se vincularam a ela nos anos de 1999 a 2013 deste trabalho, conseguiu publicar 75 artigos. O trabalho dos pesquisadores Kneipp et al. (2013) corroboram de maneira parecida com os achados desta seção, sobretudo no que tange ao destaque a USP na produção de artigos sobre o tema ora investigado. Também cabe ressaltar as IESs: ESPM, Uninove, FGV-SP, UFSM, PUC-SP, UFRGS, UFPE, Unisinos com 39, 26, 25, 21, 19, 17, 15 e 14 artigos publicados. Já os autores Moraes, Strehlau e Turolla (2015), além de destacarem em seu estudo a USP, também realçam as IESs FGV-SP, ESPM, UFRGS e Unisinos, corroborando com os resultados dessa pesquisa.

Com 12 manuscritos divulgados têm as IESs: UFRJ e UFPR. Com 11 aparecem as universidade: Univali, Unifor e Ipleiria (Portugal). As IESs: PUC-MG, PUC-RJ e Unisul publicaram todas dez artigos. Com nove papers surge a UnB; e finalmente com oito publicações têm-se as instituições: UERJ e UFPB.

20 IESs publicaram de oito a 75 artigos; 57 IESs publicaram de dois a sete papers; e a grande maioria, isto é, 92 instituições, publicaram apenas um artigo começarem a fomentar e difundir mais artigos, mediante a pro atividade de seus docentes/pesquisadores.

\subsection{Rede de coautoria}

A Figura 5 visualiza a rede de coautoria dos 654 autores identificados neste estudo, enfatizando a centralidade de grau.

A rede dos coautores visualizada pela Figura 5 tem uma densidade de 0,0045 , ou seja, menos de $1 \%$ $(0,45 \%)$ das interações entre os pesquisadores são efetivamente realizadas. Tal informação pode ser entendida em virtude da rede ter diversas outras redes de coautores dentro dela, formando com isso diversos grupos de estudos, contudo, estas parcerias são entre poucos autores e não entre si, inviabilizando uma maior conexão entre os 654 autores identificados nesta rede.

Colocam-se em evidencia também os autores: Borini, Scherer, Ferreira, Amal e Gomes por suas respectivas centralidades de grau, portanto, estes pesquisadores, por suas quantidades respectivas de laços têm maior relevância e importância como ator desta rede social (Mello; Crubellate; Rossoni, 2010). É interessante realçar que estes autores, além de se 


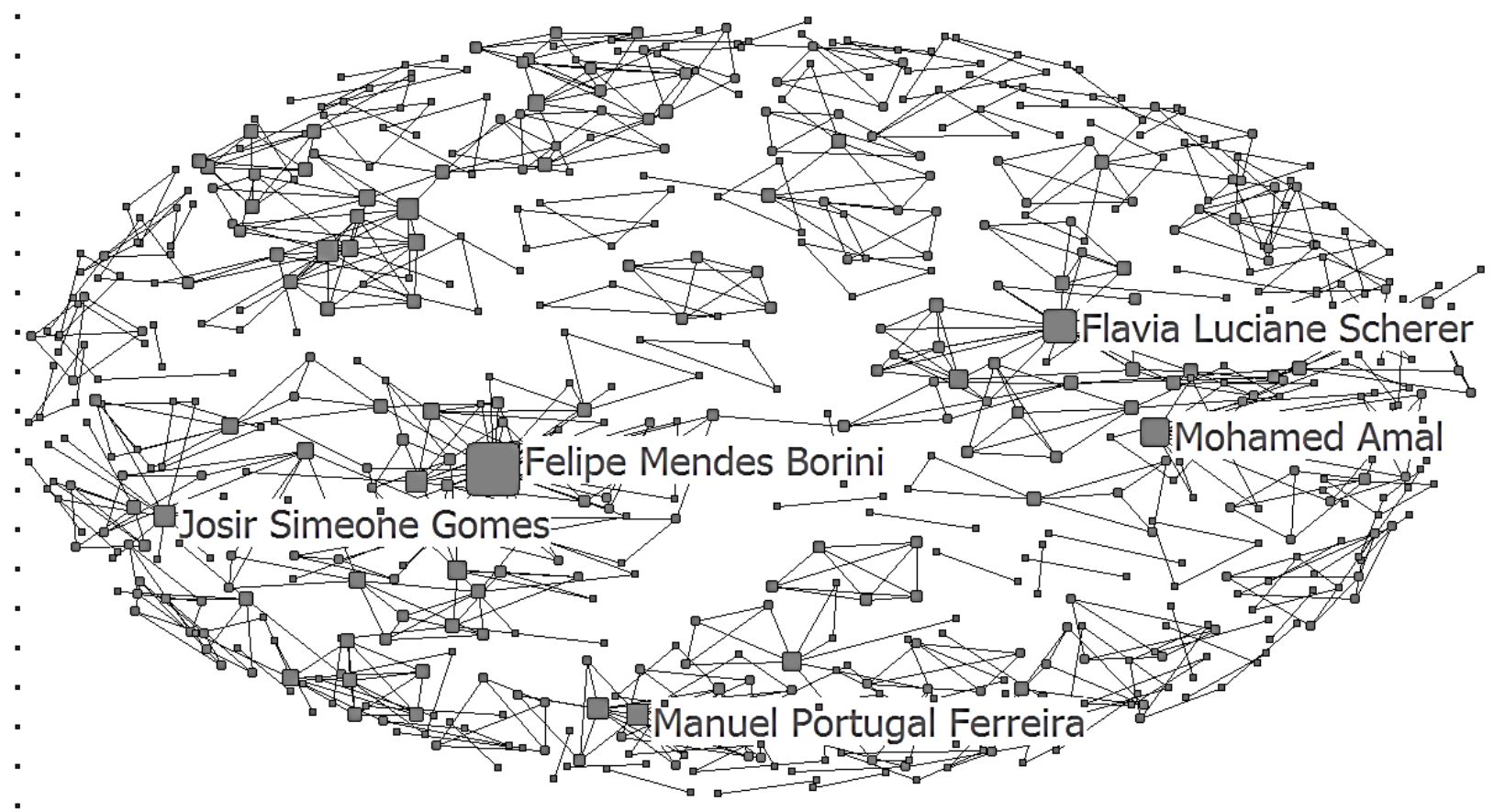

Fig. 5

Rede de coautoria

Fonte: Dados da pesquisa

destacarem como os mais centrais desta rede, também estão entre os 20 que mais produziram papers sobre internacionalização neste estudo, com especial destaque aos autores Borini, Scherer e
Ferreira, por estes estarem entre os cinco mais profícuos deste trabalho. E este achado contribui para mostrar e afirmar a proeminência e o valor que estes pesquisadores têm para a divulgação e

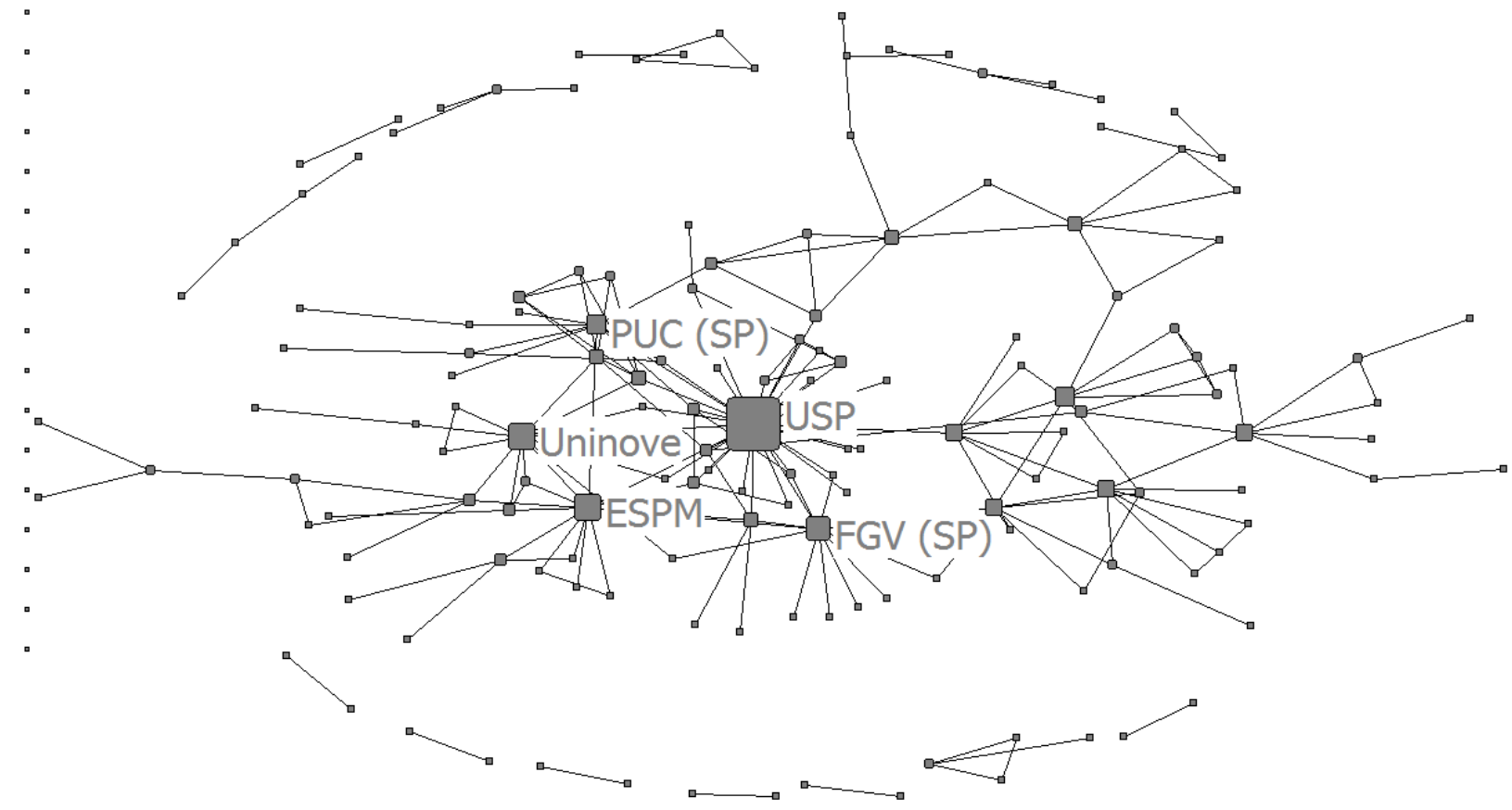

Fig. 6

Rede das IESs

Fonte: Dados da pesquisa 
disseminação do tema ora investigado na literatura acadêmica no Brasil.

\subsection{Rede das IESs}

A Figura 6 contempla a rede social das 169 IESs, concebendo assim 169 nós que são os pontos de amarração entre os atores (Ducci e Teixeira, 2011), que neste caso são as IESs. destaque da região Nordeste por meio da UFPE (vide Figuras 4 e 7), os achados desta seção e de maneira geral deste estudo, as principais regiões que dominam a publicação e evidenciação do tema internacionalização são a Sudeste e Sul (Figura 7), mediante as IESs que são oriundas dos estados que compõem tais regiões.

É importante salientar e realçar em especial as

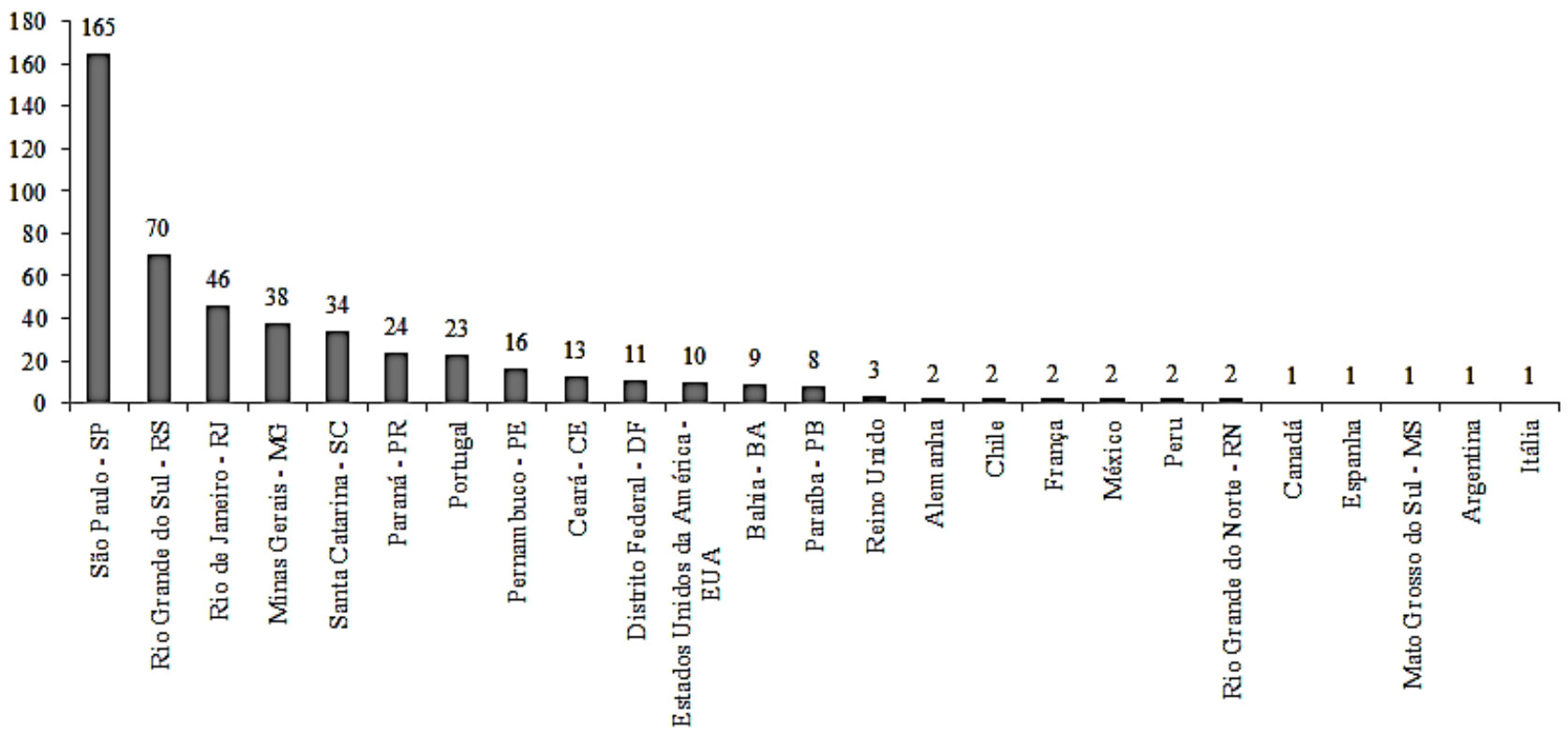

Fig. 7

Estados e países

Fonte: Dados da pesquisa

Realça-se primeiramente o destaque que as IESs: USP, ESPM, Uninove, FGV-SP e PUC-SP têm nesta rede social. Tal dado coloca em evidencia e em um nível de importância estas instituições na produção de papers sobre internacionalização no Brasil. Isto em virtude do destaque que os autores (Figura 3) vinculados a estas IESs citadas têm na produção de manuscritos sobre o tema objeto de estudo, excetuando a FGV-SP e PUC-SP que não tiveram nenhum autor entre os 18 primeiros da Figura 3 deste trabalho. Tal informação pode conceber que a FGVSP e a PUC-SP têm uma gama maior de pesquisadores, que produziram menos, porém no montante geral, isto é, somada as publicações destes citados pesquisadores influenciaram respectivamente a produção científica da FGV-SP e PUC-SP sobre o assunto internacionalização.

Os achados da Figura 6 contribuem para fornecer dados que mostram que as IESs em destaque nesta seção, são preponderantes para a divulgação e disseminação do tema ora estudado, e que apesar do

nações Portugal e EUA (Figura 7), por suas respectivas contribuições, mediante suas IESs, para o enriquecimento da temática internacionalização na literatura acadêmica brasileira, mostrando com isso que este tema tem apelo não só no âmbito nacional, mas também no panorama internacional.

\subsection{Temas abordados}

A Tabela 4 noticia as 78 temáticas abordadas nos 407 artigos explorados sobre o tema internacionalização de 1999 a 2013, sendo que estes abarcam e são inerentes ao assunto principal deste estudo.

A temática empresas multinacionais foi a mais evidenciada em 15 anos de pesquisa sobre internacionalização, com 31 artigos publicados, que nortearam de maneira dominante o citado tema. Tal achado é em virtude da importância destas empresas para a maior difusão e entendimento do assunto internacionalização (Costa e Porto, 2013), pois estas organizações expressam operações internacionais 
Tab. 4

Temas abordados

\begin{tabular}{|c|c|c|c|c|c|c|c|c|c|c|c|c|c|c|c|c|c|}
\hline Themes/Years & 99 & 00 & 01 & 02 & 03 & 04 & 05 & 06 & 07 & 08 & 09 & 10 & 11 & 12 & 13 & Total & $\%$ \\
\hline Multinational companies & & & & & & 1 & & 3 & 3 & & 3 & 10 & 1 & 5 & 5 & 31 & $7,62 \%$ \\
\hline International business & & & & & & & 1 & 1 & & 3 & 6 & 2 & 1 & 4 & 6 & 24 & $5.90 \%$ \\
\hline Innovation & & & & & & & 1 & & 2 & 2 & 1 & 5 & 5 & 2 & 5 & 23 & $5.65 \%$ \\
\hline Competitive strategy & & & & & 1 & 2 & 4 & 2 & 2 & 2 & 3 & & 3 & 1 & 1 & 21 & $5.16 \%$ \\
\hline Technologies & & & & & 1 & & 1 & & 1 & 1 & 3 & 2 & 2 & 3 & 4 & 18 & $4.42 \%$ \\
\hline Export performance & & & & & & 1 & 1 & 2 & 4 & 1 & & & 2 & 3 & 2 & 16 & $3.93 \%$ \\
\hline Small and medium-sized enterprises & & & & & & & 1 & 1 & 2 & & 3 & 3 & 1 & 2 & 2 & 15 & $3.69 \%$ \\
\hline International markets & 1 & & & 1 & 1 & & 1 & & 2 & 2 & 1 & 2 & & 2 & 2 & 15 & $3.69 \%$ \\
\hline International marketing & & & & & & 2 & 2 & 1 & 4 & & & 3 & 1 & & 1 & 14 & $3.44 \%$ \\
\hline International strategies & 1 & & & & & & 2 & 1 & & 1 & 4 & 2 & & 1 & 1 & 13 & $3.19 \%$ \\
\hline Theories of Internationalization & & & & & & & & 2 & 3 & 1 & 2 & 2 & & & 2 & 12 & $2.95 \%$ \\
\hline Research And Development (R\&D) & & & & & & & & & 2 & & 2 & 3 & & 1 & 2 & 10 & $2.46 \%$ \\
\hline Organizational culture & 1 & & & & & & & & & 2 & & 3 & 1 & 1 & 2 & 10 & $2.46 \%$ \\
\hline Strategic alliances & & & & & & 1 & 1 & 4 & & & 1 & 1 & & 1 & 1 & 10 & $2,46 \%$ \\
\hline Investments & & & & & & & 2 & & 1 & 1 & 2 & 1 & 1 & 1 & 1 & 10 & $2.46 \%$ \\
\hline Emerging markets & & & & & & 2 & & & 1 & & & & 1 & 2 & 3 & 9 & $2.21 \%$ \\
\hline Managerial control & & & 1 & & & & & 1 & & & 1 & 3 & 1 & & 1 & 8 & $1.97 \%$ \\
\hline Organizational performance & & & & & & & & & 1 & & 2 & 1 & 1 & 2 & 1 & 8 & $1.97 \%$ \\
\hline Inter-organizational networks & & & & & & 1 & & & & & 1 & 2 & 1 & 2 & 1 & 8 & $1.97 \%$ \\
\hline Uppsala model & & & & & 1 & & & 1 & 1 & & 1 & & 1 & & 3 & 8 & $1.97 \%$ \\
\hline People management & & & & & & & & & & & 1 & 1 & 1 & 1 & 3 & 7 & $1.72 \%$ \\
\hline Entrepreneurship & & & & & & & & & & 2 & & 2 & & 1 & 1 & 6 & $1.47 \%$ \\
\hline Corporate governance & & & & & & 1 & & & & & & 1 & 1 & 1 & 1 & 5 & $1.23 \%$ \\
\hline Knowledge transfer & & & & & & & & & & & 1 & & 2 & 1 & & 4 & $0.98 \%$ \\
\hline Franchising & & & & & & & & & & 1 & 1 & & 2 & & & 4 & $0.98 \%$ \\
\hline Higher education institutions (HEIs) & & & & & & & & & 1 & 1 & & & & 1 & 1 & 4 & $0.98 \%$ \\
\hline Internationalization templates & & & & & & & & & 2 & & & & 1 & 1 & & 4 & $0.98 \%$ \\
\hline Sustainability & & & & & & & & & & 1 & & 2 & & & 1 & 4 & $0.98 \%$ \\
\hline Institutional theory & & & & & & & & & 1 & & & 2 & & & 1 & 4 & $0.98 \%$ \\
\hline Resource-based view & & & & & & & & 2 & 1 & & & & & 1 & & 4 & $0.98 \%$ \\
\hline International management & & & & & & & & & 1 & 1 & & & 1 & 1 & & 4 & $0.98 \%$ \\
\hline Agribusiness & & & & & & & & 1 & & 1 & & & 1 & 1 & & 4 & $0.98 \%$ \\
\hline Positioning strategy & & & & & & & & & & & 1 & & & 1 & 2 & 4 & $0.98 \%$ \\
\hline Competitive advantage & & & & & & & & & & 1 & & 1 & & & 1 & 3 & $0.74 \%$ \\
\hline International accounting & & & & & 1 & & & & & & & & 1 & 1 & & 3 & $0.74 \%$ \\
\hline Diversification strategy & & & & & & & & 1 & & & 1 & 1 & & & & 3 & $0.74 \%$ \\
\hline Organizational structure & & & & & & & 1 & 1 & & & & & 1 & & & 3 & $0,74 \%$ \\
\hline International policy & 1 & & & & & & & & & & & & & 1 & & 2 & $0.49 \%$ \\
\hline Transnationalization & & & & & & & & & & & 2 & & & & & 2 & $0.49 \%$ \\
\hline Agency theory & & & & & & & & & 1 & 1 & & & & & & 2 & $0.49 \%$ \\
\hline Clusters & & & & & & & & & & & & & 1 & 1 & & 2 & $0.49 \%$ \\
\hline Economy & 1 & & 1 & & & & & & & & & & & & & 2 & $0.49 \%$ \\
\hline Transnational companies & & & & & 1 & & & & & & 1 & & & & & 2 & $0.49 \%$ \\
\hline Teaching and research & & & & & & & & & & 2 & & & & & & 2 & $0.49 \%$ \\
\hline Internet & & & & & & & & & & 1 & 1 & & & & & 2 & $0.49 \%$ \\
\hline Socio-Environmental Responsibility & & & & & & & & & 1 & & & 1 & & & & 2 & $0.49 \%$ \\
\hline Social capital & & & & & & & & & & & & & & 2 & & 2 & $0.49 \%$ \\
\hline Expatriation & & & & & & & & & & & & & 2 & & & 2 & $0.49 \%$ \\
\hline Globalization & & & 1 & & & & & & & 1 & & & & & & 2 & $0.49 \%$ \\
\hline Knowledge management & & & & & & & 1 & & 1 & & & & & & & 2 & $0.49 \%$ \\
\hline University-company & & & & & & & & & & & & 1 & & & & 1 & $0.25 \%$ \\
\hline Tourism & & & & & & & & & 1 & & & & & & & 1 & $0.25 \%$ \\
\hline Third sector & & & 1 & & & & & & & & & & & & & 1 & $0.25 \%$ \\
\hline Competitive intelligence & & & & & & & & & & & & & & & 1 & 1 & $0.25 \%$ \\
\hline Social Responsibility & & & & & & & & & 1 & & & & & & & 1 & $0.25 \%$ \\
\hline Behavioral approach & & & & & & & & & & & & & & & 1 & 1 & $0.25 \%$ \\
\hline Organizational learning & & & & & & & & & & & & & 1 & & & 1 & $0.25 \%$ \\
\hline Local productive arrangements & & & & & & & & & & & & & 1 & & & 1 & $0.25 \%$ \\
\hline Balanced scorecard & & & & & & & & & & & 1 & & & & & 1 & $0.25 \%$ \\
\hline BRICS & & & & & & & & & & & & 1 & & & & 1 & $0.25 \%$ \\
\hline Dynamic capabilities & & & & & & & & & & & 1 & & & & & 1 & $0.25 \%$ \\
\hline Transaction costs & & & & & & & & & & & & 1 & & & & 1 & $0.25 \%$ \\
\hline Competitive performance & & & & & & & & & & & & & 1 & & & 1 & $0.25 \%$ \\
\hline Financial performance & & & & & & & & & & & & & 1 & & & 1 & $0.25 \%$ \\
\hline Law & & & & & & & & & 1 & & & & & & & 1 & $0.25 \%$ \\
\hline Disclosure & & & & & & & & & & 1 & & & & & & 1 & $0.25 \%$ \\
\hline Ethics & & & & & & & & & & 1 & & & & & & 1 & $0.25 \%$ \\
\hline Mergers and acquisitions & & & & & & & & & & & & 1 & & & & 1 & $0.25 \%$ \\
\hline Environmental management & & & & & & & & & & & 1 & & & & & 1 & $0.25 \%$ \\
\hline Operations management & & & & & & & 1 & & & & & & & & & 1 & $0.25 \%$ \\
\hline Project management & & & & & & & & & & 1 & & & & & & 1 & $0.25 \%$ \\
\hline Risk management & & & & & & & & & 1 & & & & & & & 1 & $0.25 \%$ \\
\hline Global sourcing & & & & & & & & & & & & & 1 & & & 1 & $0.25 \%$ \\
\hline Governance in the public sector & & & & & & & & 1 & & & & & & & & 1 & $0.25 \%$ \\
\hline Capital market & & & & & & & & 1 & & & & & & & & 1 & $0.25 \%$ \\
\hline System integration model & & & & & & & & & & & & & & & 1 & 1 & $0.25 \%$ \\
\hline Decision-making process & & & & & & & & & & & & & 1 & & & 1 & $0.25 \%$ \\
\hline Retail & & & & & & & & & & 1 & & & & & & 1 & $0.25 \%$ \\
\hline Total & 5 & 0 & 4 & 1 & 6 & 11 & 20 & 26 & 42 & 33 & 48 & 60 & 43 & 48 & 60 & 407 & $100.00 \%$ \\
\hline
\end{tabular}

Fonte: Dados da pesquisa 
relativamente extensas, abrangendo com isso a movimentação internacional de bens e recursos econômicos, financeiros, tecnológicos e management (Pereira, 1976). Em seguida surge o tema negócios internacionais, prevalecendo com ênfase em 24 manuscritos divulgados. Neste contexto, ressalva-se que o mencionado assunto, por meio de suas pesquisas publicadas (Ferreira et al., 2009), é essencial para a melhor compreensão dos assuntos pertinentes e que se aplicam e consequentemente tem suas implicações sobre o tema internacionalização (Carpes et al., 2010).

O assunto inovação vem em seguida com 23 artigos divulgados, podendo ser em virtude de que a inovação é considerada necessária ao processo e ao prisma da internacionalização, sendo vista como uma estratégia organizacional (Fleury e Fleury, 2003) efetiva, possibilitando a geração de vantagem competitiva para as organizações que desejam galgar no cenário internacional (Borini et al., 2006), potencializando, aperfeiçoando e desenvolvendo estas organizações em seus padrões internacionais (Judice, Da Silva e Baeta, 2005). Em seguida vem a temática estratégia competitiva que ficou em evidencia em 21 artigos. Esta relação entre internacionalização e estratégia competitiva, deve ser pelo simples fato de que a internacionalização é uma estratégia (Contador e Stal, 2011) e que gera vantagem competitiva para as organizações que a adotam (Fleury e Fleury, 2003).

O assunto tecnologias também aparece em realce neste estudo, com 18 papers publicados. Já o tema desempenho exportador vem logo em seguida, com 16 publicações. Sendo que seu destaque, é em decorrência do mesmo ser emergente no panorama acadêmico nacional (Silva; Crespam e Scherer, 2013), por exemplo, no que se refere PME (Klotzle e Thomé, 2006). Outros assuntos que se destacaram foram: PME e mercados internacionais, ambos com 15 papers publicados. Neste panorama, compreende-se que a internacionalização pode influenciar as PME e automaticamente em seu desempenho, explorando e proporcionando com isso uma nova abordagem e efeitos para os mercados internacionais (Floriani e Fleury, 2012).

Realçam-se também os assuntos marketing internacional, estratégias internacionais e Teorias da Internacionalização, publicados com ênfase em 14, 13 e 12 artigos respectivamente. Destas, enfoca-se as Teorias da Internacionalização, pois elas ajudam a entender e compreender a essência e importância da internacionalização no cenário empresarial (Borini et al., 2006).

\section{Considerações finais}

O objetivo deste estudo foi explorar a produção acadêmica do tema Internacionalização durante o período de 1999 a 2013 nas revistas Qualis Capes B2 a A2 (triênio 2010-2012).

Observou-se uma predominância de artigos publicados em parceria. Sendo que destes autores, os mais profícuos foram: Borini, Scherer, Moraes, Ferreira e Oliveira Júnior. Ressalva-se que destes pesquisadores, três se sobressaíram também como os mais centrais da rede de coautoria, são eles: Borini, Scherer e Ferreira. O que mostra a importância e a relevância destes para a difusão, crescimento e maturação do tema internacionalização no cenário acadêmico brasileiro.

No que se refere a rede das IESs, a USP, ESPM, Uninove, FGV-SP e PUC-SP foram as mais centrais, sendo que as quatro primeiras, estão também entre as cinco mais profícuas neste estudo. Tal dado se faz relevante, pois evidencia que estas IESs são preponderantes e alicerçam, por meio de seus acadêmicos que se vinculam as mesmas, o tema internacionalização no panorama literário cientifico nacional.

Constatou-se que em suma, 11 temas foram publicados de 12 a 31 vezes. 39 assuntos foram divulgados de duas a 10 vezes. E 28 temáticas foram evidenciadas uma vez cada. Este último dado é uma oportunidade que se vislumbra neste estudo, pois contribui para quem sabe alargar e robustecer ainda mais assuntos que são inerentes ao tema principal deste trabalho que é a internacionalização. Outra contribuição relevante destes dados, é que eles fornecem um panorama de como a internacionalização, mediante suas temáticas que Ihe são inerentes, estão sendo publicadas, evidenciadas e discutidas no âmbito literário nacional, sobretudo, é também uma oportunidade de fomentar e desenvolver principalmente as temáticas ainda pouco publicadas nos periódicos nacionais estudados aqui, contribuindo com isso para um maior aperfeiçoamento do tema principal deste estudo que foi a internacionalização.

Os resultados deste estudo contribuem também para a construção, desenvolvimento, divulgação e 
socialização do conhecimento científico sobre o tema internacionalização, uma vez que comprovou, por meio dos indicadores bibliométricos e de rede social, características e tendências com relação às publicações acadêmicas sobre internacionalização divulgadas nos periódicos Qualis Capes nacionais.

Esforços como este, ou seja, de explorar a produção científica do tema objeto de estudo, contribuem para o maior discernimento e ampliação, não somente do tema em si, mas também dos assuntos que lhes são relacionados, e que foram evidenciados na Tabela 4 deste trabalho, corroborando para o desenvolvimento de novos estudos correlatos, e/ou pesquisas que usem técnicas metodológicas similares e/ou diferentes, mas que de alguma forma robusteça a produção acadêmica da abordagem Internacionalização na literatura científica no Brasil.

Este estudo limitou-se em estudar as publicações divulgadas nas revistas nacionais B2 a A2. Com isso sugere-se para futuros estudos um fomento e/ou aperfeiçoamento deste trabalho, alargando o extrato das revistas, pegando também os periódicos B5 a B3. Outra limitação é a quantidade de tempo estudado, ou seja, 15 anos. Sugere-se com isso, maximizar a temporalidade, podendo assim surgir novas evidencias e características sobre o tema internacionalização.

\section{Referências}

- AlBUQUeRQUe FILHO, J. B.; MACHADO-DA-SILVA, C. L. (2009) Práticas organizacionais e estrutura de relações no campo do desenvolvimento metropolitano. Revista de Administração Contemporânea, 13(4), p. 626-646.

- BeUREN, I. M.; SOUZA, J. C. (2008) Em busca de um delineamento de proposta para classificação dos periódicos internacionais de contabilidade para o Qualis CAPES. Revista Contabilidade \& Finanças, 19(46), p. 44-58. DOI: http://dx.doi.org/10.1590/S151970772008000100005

- BeURen, I. M.; DA SILVA, M. Z. (2014) Características bibliométricas dos artigos sobre gestão hospitalar publicados em periódicos de alto impacto. Revista Cubana de Información en Ciencias de la Salud, 25(1), p. 36-6.

- BORINI, F. M. et al. (2006) O prisma da internacionalização: um estudo de caso. Revista de Administração Faces, 5(3), p. 42-55.
- CARPes, A. de M.; Velter, A. N.; SCHereR, F. L.; LÜTZ, C. (2010) Panorama internacional das publicações em international business: levantamento por meio da base Web of Science. Revista Eletrônica de Negócios Internacionais da ESPM, 5(2), p. 117-139.

- CHUEKE, G. V.; AMATUCCI, M. (2015) O que é bibliometria? uma introdução ao fórum. Revista Eletrônica de Negócios Internacionais, 10(2), p. 15. DOI: http://dx.doi.org/10.18568/19804865.1021-5

- CONTADOR, J. C.; STAL, E. (2011) A estratégia de internacionalização da Natura: análise pela óptica da vantagem competitiva. Economia Global e Gestão, 16(2), p. 63-82.

- CORRÊA, V. S.; VALE, G. M. V. (2014) Redes sociais, perfil empreendedor e trajetórias. Revista de Administração da USP, 49(1), p. 77-88. DOI: 10.5700/rausp1132

- CORTEZIA, S. L. D.; SOUZA, Y. S. (2011) Uma análise sobre a internacionalização de pequenas empresas brasileiras da indústria de software. Brazilian Business Review, 8(4), p. 24-45.

- COSTA, P. R. da; PORTO, G. S. (2013) Proposição de uma tipologia para a internacionalização de P\&D interno e externo nas multinacionais brasileiras. Revista de Administração da USP, 48(1), p. 145164. DOI: 10.5700/rausp1079

- DUCCI, N. P. C.; TEIXEIRA, R. M. (2011) As redes sociais dos empreendedores na formação do capital social: um estudo de casos múltiplos em municípios do norte pioneiro no estado do Paraná. Cadernos EBAPE.BR, 9(4), p. 967-997.

- Ferreira, A. G. C. (2010) Bibliometria na avaliação de periódicos científicos. DataGramaZero-Revista de Ciência da Informação, 11(3), p. 1-9.

- ferreira, A. S. P. V. et al. (2013) Um estudo bibliométrico da contribuição de John Dunning na pesquisa em negócios internacionais. Revista Brasileira de Gestão de Negócios, 15(46), p. 56-75. DOI: http://dx.doi.org/10.7819/rbgn.v15i46.1163

- FERREIRA, D.; CAVALCANTI NETO, S.; GOMES, J. S. (2014) Internacionalização de empresas: uma análise bibliométrica da produção científica dos últimos cinco anos. Revista Magistro, 9(1), p. 1-23.

- FerReIRA, M. P.; LI, D.; GUISINGER, S.; SERRA, F. A. R. (2009) Is the International Business Environment the actual context for international business research? Revista de Administração de Empresas, 49(3), p. 282-294. DOI: http://dx.doi.org/10.1590/S003475902009000300004 
- FERREIRA, M. P.; SERRA, F. R.; ALMEIDA, M. I. R. (2012) Estudo bibliométrico da contribuição de Buckley e Casson (1976) na pesquisa em negócios internacionais. Revista de Ciências da Administração, 14(33), p. 9-24. DOI: http://dx.doi.org/10.5007/21758077.2012v14n33p9

- FleURY, A. C. C.; FLEURY, M. T. L. (2003) Estratégias competitivas e competências essenciais: perspectivas para a internacionalização da indústria no Brasil. Gestão \& Produção, 10(2), p. 129-144.

- FloRIANI, D. E.; FLEURY, M. T. (2012) O efeito do grau de internacionalização nas competências internacionais e no desempenho financeiro da PME brasileira. Revista de Administração Contemporânea, 16(3), p. 438-458.

- GOMES, J. S.; OLIVEIRA, R. R.; VIEIRA, S. S. C. (2011) Inserção do tema internacionalização de empresas em artigos produzidos no programa de mestrado em ciências contábeis da UERJ. Revista Eletrônica Sistemas \& Gestão, 6, p. 508-520.

- DOI: http://dx.doi.org/10.7177/sg.2011.V6.N4.A7

- GONZÁLEZ-VALIENTE, C. L. (2015) 0 Análisis del impacto de las investigaciones publicadas por Internext - Revista Eletrônica de Negócios Internacionais. Revista Eletrônica de Negócios Internacionais, 10(2), p. 6-17.

- GuEDES, A. L. (2006) Internacionalização de empresas como política de desenvolvimento: uma abordagem de diplomacia triangular. Revista de Administração Pública, 40(3), p. 335-356.

- GUIDO, A. L. B.; LIMA, R. T. (2012) Empresas transnacionais e internacionalização: uma análise bibliométrica dos termos. Revista Brasileira de Administração Científica, 3(3), p. 83-96.

- DOI: http://dx.doi.org/10.6008\%2FESS2179684X.2012.003.0006

- guimarães, S. R. E. F.; TAdeucCl, M. de S.; OLIVEIRA, A. L. (2013) Estudo bibliométrico em gestão intercultural, internacionalização e mobilidade acadêmica: foco no ensino superior. Janus, 17, p. 55-65.

- HILAL, A.; HeMAIS, C. A. (2003) O processo de internacionalização na ótica da escola nórdica: evidências empíricas em empresas brasileiras. Revista de Administração Contemporânea, 7(1), p. 109-124. DOI: http://dx.doi.org/10.1590/S141565552003000100006

- JUdiCE, V. M. M.; DA SILVA, S. M.; BAETA, A. M. C. (2005) Inovação e internacionalização bioindustrial em Minas Gerais 2001-2004: como potencializar oportunidades e avançar rumo a 2020? Cadernos EBAPE.BR, 3(especial), p. 01-17. DOI: $\quad$ http://dx.doi.org/10.1590/S167939512005000500009

- KLOTZle, M. C.; THOMÉ, C. C. (2006) Fatores associados ao desempenho exportador de micros, pequenas e médias empresas brasileiras. Revista de Administração da USP, 41(3), p. 339-346.

- KNEIPP, J. M. et al. (2013) O processo de internacionalização de empresas: uma análise da produção científica brasileira. Revista Global Manager, 13(1), p. 22-43.

- DOI: http://dx.doi.org/10.1590/S008021072006000300010

- $\quad$ kOVACS, E, P.; MORAES, W. F. A. de; OliveirA, B. R. B. (2011) Características da localização no processo de internacionalização de empresas. Revista de Administração de Empresas, 51(4), p. 320-335.

- $\quad$ KOVACS, E. P.; MORAES, W. F. A.; OLIVEIRA, B. R. B. (2007) Redefinindo conceitos: um ensaio teórico sobre os conceitos-chave das teorias de internacionalização. Revista de Gestão USP, 14(especial) p. 17-29.

- Leite filho, G. A. (2008) Padrões de produtividade de autores em periódicos e congressos na área de contabilidade no Brasil: um estudo bibliométrico. Revista de Administração Contemporânea, 12(2), p. 533-554.

- Machado neto, A. J.; AlMeidA, F. C. (2008) A internacionalização da indústria calçadista francana. Revista de Administração Mackenzie, 9(8), p. 88-111.

- MARTINS, G. S. et al. (2010) Gestão de operações no Brasil: uma análise do campo científico a partir da rede social de pesquisadores. RAE eletrônica, 9(2), p. 1-26.

- Mello, C. M. de; CRUBellate, J. M.; ROSSONI, L. (2010) Dinâmica de relacionamento e prováveis respostas estratégicas de programas brasileiros de pós-graduação em administração à avaliação da capes: proposições institucionais a partir da análise de redes de co-autorias. Revista de Administração Contemporânea, 14(3), p. 434-457.

- Moraes, S. G.; StRehlaU, V. I.; TUROLla, F. A. (2015) Produção acadêmica de autores brasileiros sobre Internacionalização: Balanço das publicações no Brasil no Séc. XXI. Revista Eletrônica de Negócios Internacionais, 10(2), p. 82-96. DOI: http://dx.doi.org/10.18568/1980-4865.10282-96 
- MORAES, W. F. A.; OLIVEIRA, B. R. B.; KOVACS, E. P. (2006) Teorias de internacionalização e aplicação em países emergentes: uma análise crítica. Revista Eletrônica de Negócios Internacionais da ESPM, 1(1), p. 203-220. DOI: http://dx.doi.org/10.18568/1980-4865.11221242

- MOREIRA, A. C. (2009) The evolution of internationalization: towards a new theory? Economia Global e Gestão, 14(1), p. 41-59.

- ogasavara, M. h.; MAsiero, g.; mota, M. O.; CORREIO, L. S. (2015) Research on brazilian multinational enterprises: descriptive and predictive analyses. Revista Eletrônica de Negócios Internacionais, 10(2), p. 64-81. DOI: http://dx.doi.org/10.18568/1980-4865.10264-81

- PACHECO, R. C. DOS S.; KERN, V. M. (2001) Uma ontologia comum para a integração de bases de informações e conhecimento sobre ciência e tecnologia. Ciência da Informação, 30(3), p. 56-63.

- PAIVA, E. L.; HEXSEL, A. E. (2005) Contribuição da Gestão de Operações para a Internacionalização de Empresas. Revista de Administração Contemporânea, 9(4), p. 73-95. DOI: http://dx.doi.org/10.1590/S141565552005000400005

- Pereira leite, Y. V.; MORAES, W. F. A. (2014) Facetas do Risco no Empreendedorismo Internacional. Revista de Administração Contemporânea, 18(1), p. 96-117.

- PEREIRA, L. C. B. (1976) Um estudo sobre as empresas multinacionais no Brasil. Revista de Administração de Empresas, 16(1), p. 42-45. DOI: http://dx.doi.org/10.1590/S003475901976000100006
- RIBEIRO, H. C. M. (2014) Quinze anos de produção acadêmica do tema contabilidade internacional: uma análise bibliométrica em periódicos brasileiros. Revista de Educação e Pesquisa em Contabilidade, 8(3), p. 326-343. DOI: http://dx.doi.org/10.17524/repec.v8i3.1079

- SANTOS, V. et al. (2011) Internacionalização em trabalhos publicados no Enanpad no período de 2005 a 2009: uma análise bibliométrica. Revista da Unifebe, 9, p. 1-20.

- SCARPIN, M. R. S. et al. (2012) Análise bibliométrica de artigos de clusters e internacionalização em periódicos de alto impacto no período de 2000 a 2010. Revista da Unifebe, 10, p. 123-140.

- SILVA, V. A.; CRESPAM, C. C.; SCHERER, F. L. (2013) Performance exportadora: uma análise da produção científica brasileira. Revista Eletrônica de Negócios Internacionais da ESPM, 8(2), p. 22-39. DOI: http://dx.doi.org/10.18568/1980-4865.822239

- souzA, E. C. L.; FENILI, R. R. (2012) Internacionalização de empresas: perspectivas teóricas e agenda de pesquisa. Revista de Ciências da Administração, 14(33), p. 103-118. DOI: http://dx.doi.org/10.5007/21758077.2012v14n33p103

- SPOHR, N.; SILVEIRA, F. F. (2012) Estratégia internacional de uma multinacional emergente brasileira: o caso JBS. Revista de Administração de Empresas, 52(3), p. 300-312.

- VANTI, N. A. P. (2002) Da bibliometria à webometria: uma exploração conceitual dos mecanismos utilizados para medir o registro da informação e a difusão do conhecimento. Ciência da Informação, 31(2), p. 152-162.

\section{Sobre o autor}

- Henrique César Manuel Ribeiro é Doutor em Administração pela Universidade Nove de Julho - Uninove. Professor na Universidade Federal do Piaui atuando nas linha de pesquisas: Estratégia e Estudos Organizacionais - UFPI, Parnaíba, PI, Brasil.E-mail: hcmribeiro@gmail.com 


\title{
Academic production on the theme of internationalization in national journals: A bibliometric study
}

\author{
Henrique César Melo Ribeiro
}

Federal University of Piaui - UFPI, Parnaíba, PI, Brazil

ARTICLE DETAILS
Article history:
Received 16 October 2014
Accepted 9 October 2015
Available online in 30 April 2016
Double Blind Review System
Scientific Editor
Eduardo Eugênio Spers

\section{Keywords:}

Internationalization

Academic production

Bibliometric study

\begin{abstract}
This study explored academic production on the theme of internationalization between 1999 and 2013 in academic journals, ranking from Capes/Qualis B2 to A2 (triennium 2010-2012). Methodologically, bibliometric and social networking analysis techniques were used. The main findings were: Borini, Scherer, Amal, Ferreira, and Gomes were highlighted for their co-authorship with regard to degree centrality. The higher education institutions (HEIs) USP, ESPM, and Uninove stand out in the social network of HEls with respect to their degree. All social networks displayed in this work have low densities. The most published themes were: multinational companies, international business, innovation, competitive strategy, technology, export performance, small and medium-sized enterprises (SMEs), international markets, international marketing, and international strategies. These themes were highlighted in this study and are inherent in internationalization, showing coherence to the topic explored and, above all, that this subject is broad, because it addresses prevalent themes for the better understanding of the processes that drive internationalization in a global context.
\end{abstract}

(C) 2016 Internext | ESPM. All rights reserved! 